\title{
Experimental behaviour of stainless steel plate girders under combined
}

\section{bending and shear}

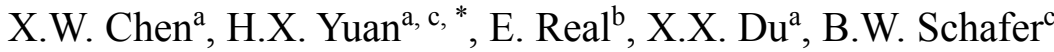 \\ ${ }^{\text {a } H u b e i}$ Provincial Key Laboratory of Safety for Geotechnical and Structural Engineering, School of Civil Engineering, Wuhan \\ University, Wuhan 430072, PR China \\ ${ }^{b}$ Department of Civil and Environmental Engineering, Universitat Politècnica de Catalunya, Barcelona 08034, Spain \\ ${ }^{\mathrm{c}}$ Department of Civil Engineering, Johns Hopkins University, Baltimore, MD 21218, United States
}

Corresponding author:

Dr Huanxin Yuan, School of Civil Engineering, Wuhan University, Wuhan 430072, China. Email: yuanhx@ whu.edu.cn

\begin{abstract}
The behaviour of stainless steel plate girders subjected to combined bending and shear was experimentally studied in this paper. Both tensile and compressive material properties of the two adopted stainless steel alloys, including austenitic grade EN 1.4301 and duplex grade EN 1.4462, were determined by standard coupon tests. The three-dimensional (3D) optical scanning technology was introduced to acquire an accurate distribution of initial geometric imperfections for each plate girder specimen. A total of six plate girders were fabricated by hot-rolled stainless steel plates, and were tested to failure under combined bending and shear. In-depth analyses of the critical buckling characteristics, the ultimate resistances and the collapse behaviour of the tested specimens were all presented. The obtained ultimate resistances were further employed to assess the existing moment and shear (M-V) interaction design methods in EN 1993-1-5, GB 50017-2017, ANSI/AISC 360-16 and SEI/ASCE 8-02, and the design proposal presented by Jáger et al. It has been found that most of the existing codified M-V interaction formulae can be applicable for both carbon steel and stainless steel plate girders, yet they lead to relatively conservative predictions for stainless steel plate girders, except that the design method in ANSI/AISC 360-16 provides apparently unsafe strength predictions.
\end{abstract}

Keywords: Bending and shear interaction; Buckling behaviour; Experimental tests; Stainless steel; Plate girders

\section{Introduction}

Loads that act transversely on plate girders generate both bending moment and shear force, wherein the interior web panels may be subjected to a combination of high bending moment and high shear force. Hence the interaction between bending and shear should be considered when designing webs of plate girders. Basler [1] proposed an analytical model for slender web panels considering this interaction effect. It is assumed that when the bending moment is lower than the flange resistance, the web panel will be capable of transferring its allotted moment to the flanges, and therefore the shear capacity of the web panel is independent of the bending moment, and no interaction between bending and shear can be found in this case. On the contrary, in the case of higher bending moment applied, the part that carried by the web panel causes reduction in shear capacity of the web panel, thereby producing the $\mathrm{M}-\mathrm{V}$ interaction.

The Basler's model has been served as a basis for most of the codified interaction expressions for steel plate girders and other design proposals developed by many researchers. A modified version of Basler's formula has been incorporated into both European code EN 1993-1-5 [2] and Chinese code GB 50017-2017 [3] for considering the M$\mathrm{V}$ interaction effect for steel plate girders. However, this $\mathrm{M}-\mathrm{V}$ interaction effect is neglected in the current editions of American specifications ANSI/AISC 360-16 [4] and AASHTO [5] for steel plate girders, while a tri-linear expression for cold-formed beams subjected to combined bending and shear is adopted by the American code AISI S100-16 [6]. Moreover, the EN 1993-1-5 [2] interaction formula was found to be rather conservative due to the inadequate consideration of the effective restraints from flanges by Hendy and Presta [7]. While in the experimental and numerical 
studies reported by Sinur and Beg [8-9], it was demonstrated that the EN 1993-1-5 interaction curve was relatively optimistic, since the required partial safety factor was higher than the codified recommendation. More recently, Jáger et al. [10-11] conducted numerical studies on plate girders with slender webs, and proposed a revised form of M-V interaction expression for both transversely stiffened and longitudinally stiffened plate girders, which was modified from the expression presented by Sinur and Beg [9]. Shahabian and Roberts [12] developed a rounded M-V relationship for slender plate girders, and Lee et al. [13] proposed a revised design expression by considering the cross-sectional properties in the $\mathrm{M}-\mathrm{V}$ interaction diagram.

The nonlinear material behaviour of stainless steels [14] that differs significantly from ordinary carbon steels has attracted extensive studies on structural stainless steel members [15-18], and has enabled separate design provisions in existing design codes, such as European code EN 1993-1-4+A1 [19], American specification SEI/ASCE 8-02 [20] and Chinese standard CECS 410 [21]. However, the latest edition of EN 1993-1-4+A1 [19] does not provide separate design formulae for stainless steel plate girders under combined bending and shear; the related design formulae in SEI/ASCE 8-02 [20] are the same with those for cold-formed carbon steels; and the M-V interaction expressions in CECS 410 [21] do not take into account the postbuckling capacities, with few test results being available for the required verification. Moreover, the existing experimental studies [22-27] on stainless steel plate girders have mainly focused on the shear response, involving the critical shear buckling and postbuckling behaviour, yet little attention has been paid to the interaction effect between bending and shear. In view of the absence of a distinct yielding plateau and the considerable strain hardening capacity of stainless steels, the necessity of further research work for $\mathrm{M}-\mathrm{V}$ interaction of stainless steel plate girders has been highlighted.

This paper presents experimental tests performed on six stainless steel plate girders subjected to a combination of bending moment and shear force. The critical buckling and postbuckling behaviour of slender web panels were obtained and carefully analysed, revealing the interaction effect between bending and shear. The assessment and analysis of existing M-V interaction methods in EN 1993-1-5 [2], GB 50017-2017 [3], ANSI/AISC $360-16$ [4], SEI/ASCE 8-02 [20], and the proposal of Jáger et al. [10] were also presented.

\section{Experimental programme}

\subsection{Specimens}

Six plate girders made of austenitic grade EN 1.4301 and duplex grade EN 1.4462 were designed and fabricated by hot-rolled stainless steel plates. The constitutive plates of each specimen were cut in parallel to the rolling direction of hot-rolled coil. The cross-sections were built up by shielded metal arc welding (SMAW) using stainless steel electrodes, wherein type E308 electrodes were employed for grade EN 1.4301 and E2209 electrodes were adopted for grade EN 1.4462. However, the welding residual stresses of the test specimens were not experimentally studied in this paper, since the previously proposed distributive models in a separate paper [28] can be applicable to cross-sections made of both material grades.

The nominal span of each plate girder specimen was set equal to four times of the web panel width, with high bending moment and high shear force acting simultaneously on the interior web panel. Additional double sided transverse stiffeners, located at the centre of the web panels close to both ends, were used to prevent shear bucking. The geometry of the plate girder specimens is shown in Fig. 1, and the average measured dimensions for each specimen are listed in Table 1, where $\lambda_{\mathrm{w}}$ is the web slenderness parameter defined in EN 1993-1-5 [2], $w_{0}$ is the initial local geometric imperfection amplitude measured by the three-dimensional (3D) optical scanning technique, and all other symbols are illustrated in Fig. 1. The nominal thickness of web panels is $4 \mathrm{~mm}$, with two different web depths $h_{\mathrm{w}}$ and aspect ratios $a / h_{\mathrm{w}}$, resulting in a range of the web slenderness $\lambda_{\mathrm{w}}$ varying from 0.73 to 2.07 . The specimens are labelled in accordance with the stainless steel grade and nominal geometric dimensions. For example, the label VM-304-600ad1 indicates a plate girder made of grade EN 1.4301, having a web panel with nominal depth of $600 \mathrm{~mm}$ and aspect ratio 
equal to 1.0. It is worth noting that according to the provisions stipulated in EN 1993-1-4+A1 [19], all cross-sectional geometries fulfilled the requirement for web sensitivity check against shear buckling, and except for specimen VM304-300ad1 (Class $3 \mathrm{web}$ ), the other five plate girders were designed to be slender cross-sections with Class 4 webs subjected to bending. Meanwhile, by referring to the previous tests on stainless steel plate girders, moderate flanges with nominal thickness ratio $t_{\mathrm{f}} / t_{\mathrm{w}}$ of 2.0 were employed, which can lead to more prominent bending and shear interaction effect.

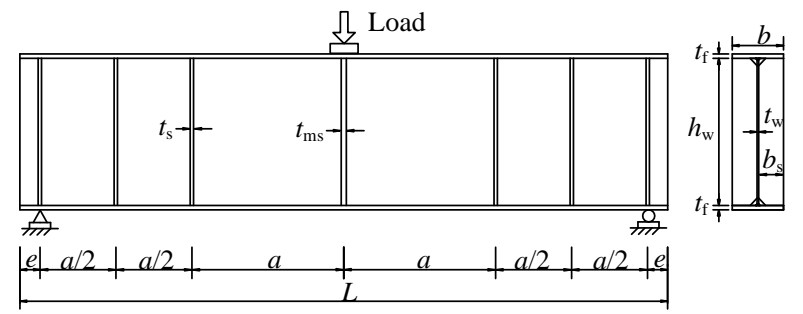

Fig. 1. Geometry of plate girder specimens

\section{Table 1}

Measured geometric dimensions for the plate girder specimens

\begin{tabular}{cccccccccccccc}
\hline Specimens & Material & $L$ & $a$ & $e$ & $h_{\mathrm{w}}$ & $b$ & $t_{\mathrm{f}}$ & $t_{\mathrm{w}}$ & $t_{\mathrm{ms}}$ & $t_{\mathrm{s}}$ & $\lambda_{\mathrm{w}}$ & \multicolumn{3}{c}{ Imperfection amplitude $w_{0}$} \\
\cline { 5 - 9 } & & & & & & & & & & & Web & Flange \\
\hline VM-304-300ad1 & 1.4301 & 1357.2 & 299.2 & 80.2 & 297.4 & 134.0 & 7.85 & 4.11 & 11.85 & 7.85 & 0.73 & 0.53 & 0.54 \\
VM-304-300ad1.5 & 1.4301 & 1955.4 & 448.8 & 80.1 & 297.9 & 134.0 & 7.85 & 3.82 & 11.85 & 7.85 & 0.90 & 0.67 & 0.55 \\
VM-304-600ad1 & 1.4301 & 2558.0 & 599.3 & 80.4 & 598.0 & 180.0 & 7.85 & 3.82 & 11.85 & 7.85 & 1.58 & 3.98 & 3.76 \\
\hline VM-2205-300ad1 & 1.4462 & 1356.6 & 299.0 & 80.3 & 297.7 & 134.0 & 7.72 & 3.90 & 12.59 & 7.72 & 1.03 & 1.53 & 0.94 \\
VM-2205-300ad1.5 & 1.4462 & 1956.8 & 449.1 & 80.2 & 297.3 & 134.0 & 7.72 & 3.90 & 12.59 & 7.72 & 1.17 & 1.11 & 0.74 \\
VM-2205-600ad1 & 1.4462 & 2556.0 & 598.9 & 80.2 & 598.1 & 180.0 & 7.72 & 3.90 & 12.59 & 7.72 & 2.06 & 4.84 & 2.78 \\
\hline All
\end{tabular}

All dimensions are in $\mathrm{mm}$.

\subsection{Initial local geometric imperfections}

A 3D optical scanning system, as shown in Fig. 2, was employed in this study to acquire an accurate initial local geometric imperfection distribution of each specimen. The scanning system employing the same principle of human stereoscopic vision [29], contained two video cameras that were placed a certain distance apart with constant angle and thereby enabled a fast scanning that would capture the accurate 3D surface topography of plate girder specimens. A single scanning operation can acquire the cloud of data points of finite area, and hence multiple scanning operations have been continuously launched at various locations to generate the whole body digital model, as shown in Fig. 3 (a). By comparing the scanned 3D model with the perfect geometric model, a complete mapping between the two models is described in Fig. 3 (b), indicating the measured distribution of geometric imperfections. Fig. 4 presents the imperfection distributions of three representative cross-sections, including two cross-sections of interior web panels and one horizontal cross-section at mid-height.

It can be noted that all plate girder specimens exhibited relatively small global imperfections, and the peak value of local imperfections was obtained close to the centre of the interior web panels. The acquired local imperfection amplitudes for all the specimens are summarised in Table 1, where the listed imperfection amplitudes from both flanges and web were obtained from the same cross-section at which the peak imperfection of the web panel was achieved. This is due to the fact that the plate girder specimens with greater geometric imperfections in the slender web panel can be more susceptible to buckling, though the actual peak imperfections from the web panel and the flanges may not coincide at the same cross-section. Moreover, the maximum imperfection amplitude of the flanges was found to be located at the end of the specimens, which had negligible effects on the buckling phenomenon studied in this paper. 


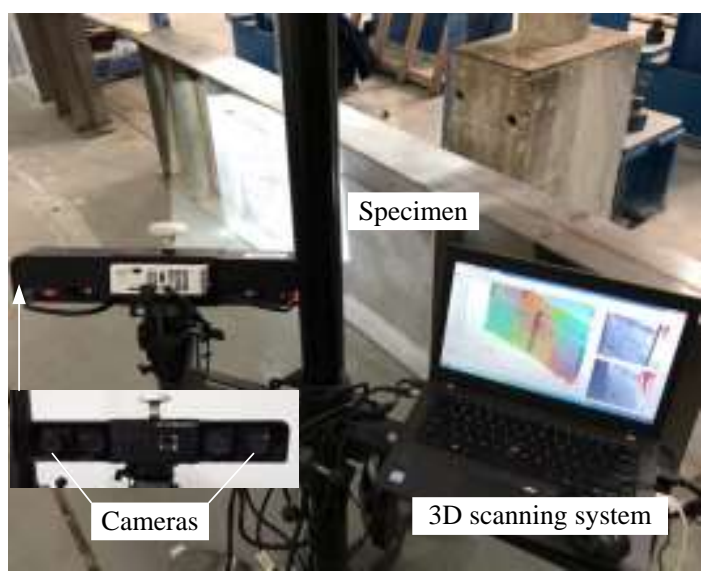

Fig. 2. 3D optical scanning system

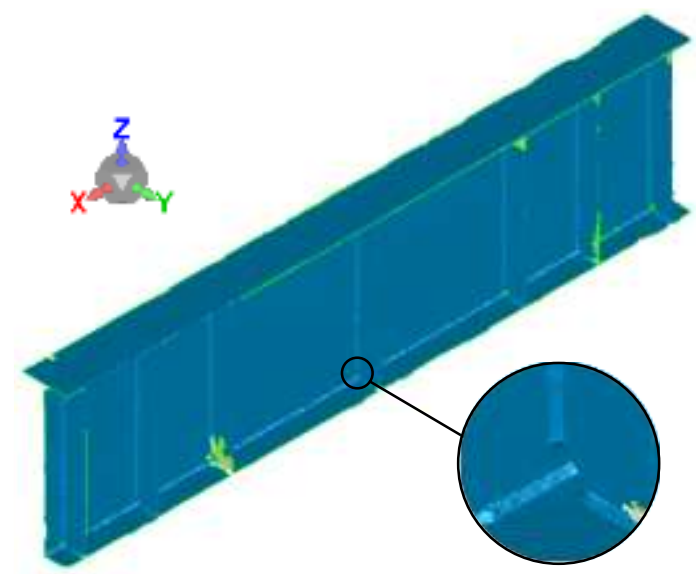

(a) 3D scanned model

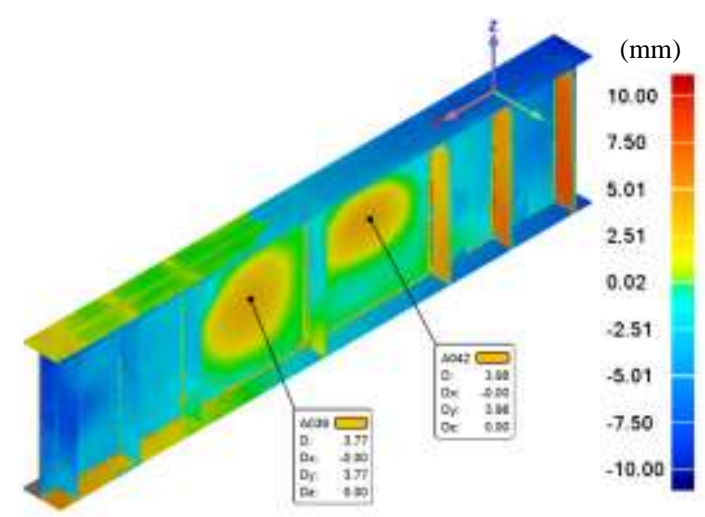

(b) 3D comparison

Fig. 3. Initial imperfection distribution of specimen VM-304-600ad1

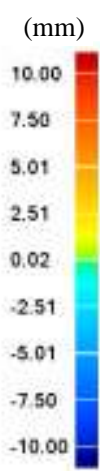

A

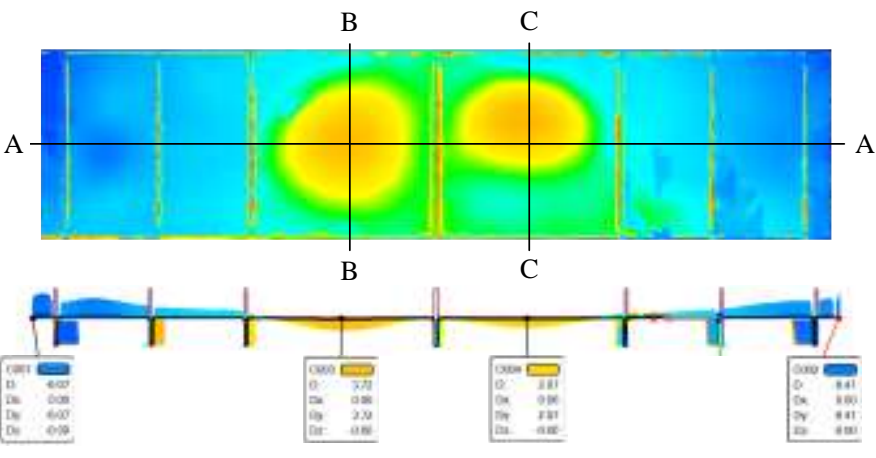

Section A-A

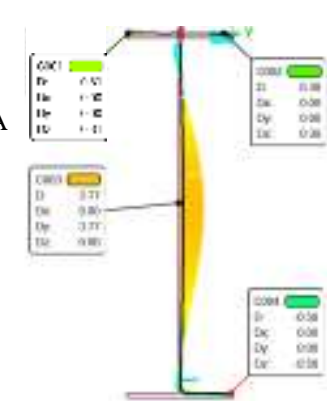

Section B-B

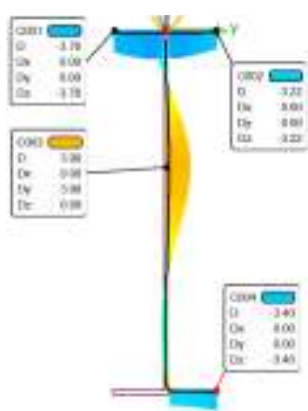

Section C-C

Fig. 4. Cross-sectional imperfections of specimen VM-304-600ad1

\subsection{Material properties}

A series of standard coupon tests was conducted to determine material properties of the two adopted stainless steel alloys. Both tensile and compressive coupons were machined from the hot-rolled coil plates in longitudinal direction, and three repeated coupons were prepared for each material grade and thickness. The tensile coupon tests have been reported in detail previously [26]. The compressive coupons were tested by using a $300 \mathrm{kN}$ capacity universal testing machine, as shown in Fig. 5. A special bracing jig, similar to the device used in the previous study [30], was adopted herein to prevent premature failure by minor axis buckling, and two unidirectional strain gauges were attached for 
each compressive coupon. The obtained stress-strain curves for the two stainless steel grades are plotted in Fig. 6, and for illustration purposes, rather than presenting the full stress-strain curves of tensile coupons, the initial parts of those are displayed. The average material properties from tensile and compressive coupons are tabulated in Tables 2 and 3, respectively, where the following symbols are used: $E_{0}$ is the Young's modulus determined from the slope of the initial linear portion of the stress-strain curves, $\sigma_{0.01}, \sigma_{0.05}, \sigma_{0.2}$ and $\sigma_{1.0}$ are the $0.01 \%, 0.05 \%, 0.2 \%$ and $1.0 \%$ proof stresses, respectively, $\sigma_{\mathrm{u}}$ is the ultimate tensile stress, $\varepsilon_{\mathrm{y}}$ and $\varepsilon_{\mathrm{u}}$ are the strains at the $0.2 \%$ proof stress and ultimate tensile stress, respectively, $\varepsilon_{\mathrm{f}}$ is the plastic strain at fracture measured from the fractured tensile coupons as elongation over the standard gauge length, $n_{\text {Test }}$ and $m_{\text {Test }}$ are the strain hardening exponents obtained by fitting the representative set of test data by means of the least squares optimisation approach.

It can be found that the material properties obtained from the tensile tests are generally higher than those from compressive tests, while this difference became much smaller with the increase of stress values. For example, the average ratios of tensile to compressive stresses $(0.01 \%$ and $0.2 \%$ proof stresses) are equal to 1.27 and 1.05 , respectively, and the mean ratio of tensile to compressive strain hardening exponent $n_{\text {Test }}$ is calculated to be 1.60 for all the values given in Tables 2 and 3, indicating noticeable asymmetry stress-strain responses between the tensile and compressive coupons, yet only $2 \%$ deviation was found for the $1.0 \%$ proof stress. Moreover, it is evident that the austenitic grade EN 1.4301 exhibits relatively lower nominal yield strength but much more considerable strain hardening capacity and higher ductility than the duplex grade EN 1.4462, while their ultimate tensile strengths are close to each other.

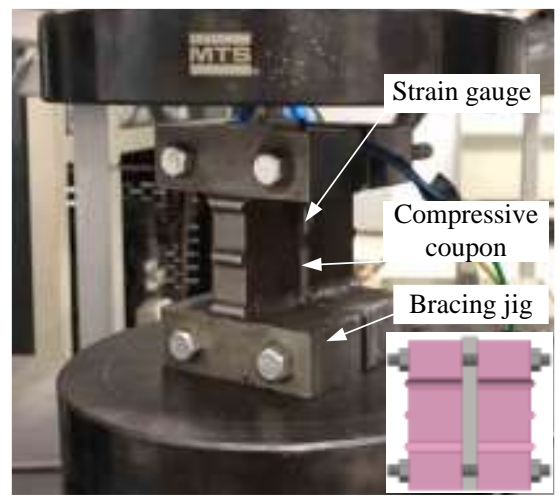

Fig. 5. Test setup for compressive coupon tests

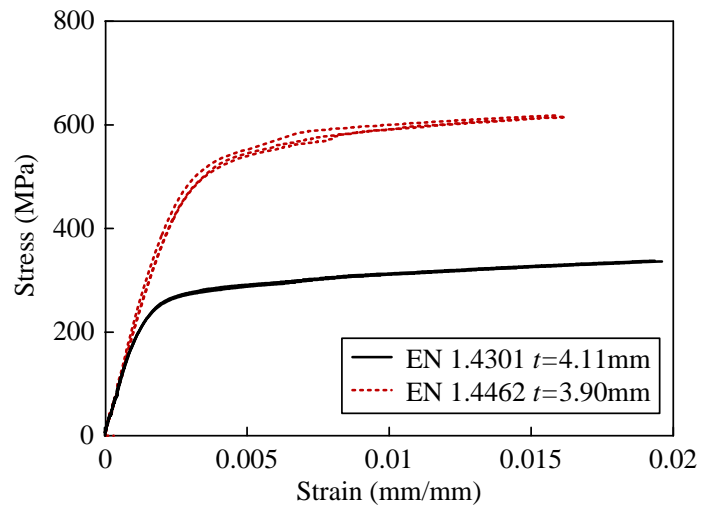

(a) Tensile coupons - initial part

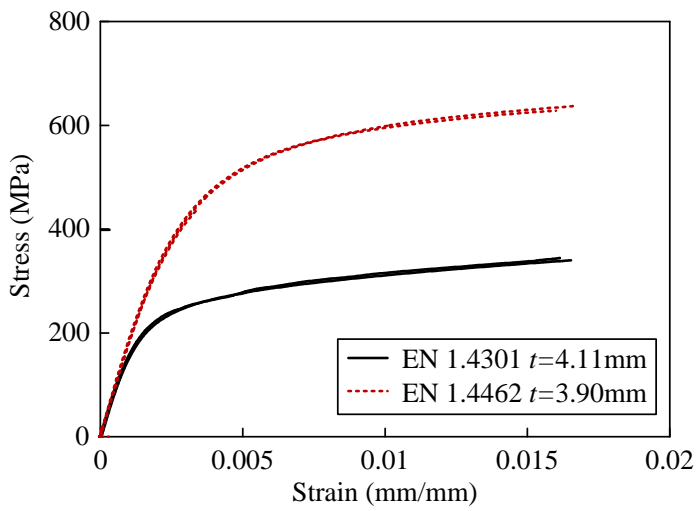

(b) Compressive coupons

Fig. 6. Stress-strain curves of tensile and compressive coupon tests 
Table 2

Measured material properties from tensile coupon tests

\begin{tabular}{|c|c|c|c|c|c|c|c|c|c|c|c|c|}
\hline \multirow{2}{*}{ Grade } & \multirow{2}{*}{$\begin{array}{c}t \\
(\mathrm{~mm})\end{array}$} & \multirow{2}{*}{$\begin{array}{c}E_{0} \\
(\mathrm{MPa})\end{array}$} & \multirow{2}{*}{$\begin{array}{c}\sigma_{0.01} \\
(\mathrm{MPa})\end{array}$} & \multirow{2}{*}{$\begin{array}{c}\sigma_{0.05} \\
(\mathrm{MPa}\end{array}$} & \multirow{2}{*}{$\begin{array}{c}\sigma_{0.2} \\
(\mathrm{MPa})\end{array}$} & \multirow{2}{*}{$\begin{array}{c}\sigma_{1.0} \\
(\mathrm{MPa})\end{array}$} & \multirow{2}{*}{$\begin{array}{c}\sigma_{\mathrm{u}} \\
(\mathrm{MPa})\end{array}$} & \multirow{2}{*}{$\begin{array}{c}\varepsilon_{\mathrm{y}} \\
(\%)\end{array}$} & \multirow{2}{*}{$\begin{array}{c}\varepsilon_{\mathrm{u}} \\
(\%)\end{array}$} & \multirow{2}{*}{$\begin{array}{c}\varepsilon_{\mathrm{f}} \\
(\%)\end{array}$} & \multicolumn{2}{|c|}{ Exponents } \\
\hline & & & & & & & & & & & $n_{\text {Test }}$ & $m_{\text {Test }}$ \\
\hline 1.4301 & 3.82 & 193500 & 237.4 & 267.2 & 289.2 & 326.4 & 783.9 & 0.35 & - & 64.2 & 15.8 & 1.8 \\
\hline 1.4301 & 4.11 & 189000 & 192.3 & 246.9 & 279.7 & 316.8 & 756.3 & 0.34 & - & 69.5 & 11.6 & 1.8 \\
\hline 1.4301 & 7.85 & 180700 & 191.4 & 247.7 & 291.7 & 338.9 & 706.0 & 0.36 & - & 62.9 & 9.4 & 2.4 \\
\hline 1.4301 & 11.85 & 182800 & 184.7 & 240.1 & 280.4 & 319.1 & 719.6 & 0.35 & - & 57.7 & 9.0 & 2.0 \\
\hline 1.4462 & 3.90 & 204800 & 345.3 & 459.6 & 539.6 & 604.1 & 761.4 & 0.46 & 26.1 & 40.2 & 8.9 & 3.6 \\
\hline 1.4462 & 7.72 & 188700 & 296.5 & 442.5 & 551.4 & 614.5 & 738.4 & 0.49 & 19.3 & 33.0 & 6.7 & 3.8 \\
\hline 1.4462 & 12.59 & 184000 & 227.8 & 349.4 & 464.6 & 552.8 & 705.3 & 0.45 & 23.3 & 37.4 & 4.8 & 3.9 \\
\hline
\end{tabular}

Table 3

Measured material properties from compressive coupon tests

\begin{tabular}{ccccccc}
\hline Grade & $t(\mathrm{~mm})$ & $E_{0}(\mathrm{MPa})$ & $\sigma_{0.01}(\mathrm{MPa})$ & $\sigma_{0.2}(\mathrm{MPa})$ & $\sigma_{1.0}(\mathrm{MPa})$ & Exponent $n_{\text {Test }}$ \\
\hline 1.4301 & 3.82 & 178000 & 148.6 & 258.3 & 323.0 & 6.8 \\
1.4301 & 4.11 & 179200 & 146.3 & 267.3 & 317.3 & 6.8 \\
1.4301 & 7.85 & 192200 & 152.0 & 288.3 & 346.6 & 6.2 \\
1.4301 & 11.85 & 180600 & 144.5 & 270.3 & 334.1 & 5.7 \\
\hline 1.4462 & 3.90 & 187200 & 243.1 & 501.4 & 618.0 & 4.9 \\
1.4462 & 7.72 & 184700 & 279.3 & 526.9 & 641.1 & 5.5 \\
1.4462 & 12.59 & 182800 & 246.5 & 465.2 & 575.0 & 5.5 \\
\hline
\end{tabular}

The strain hardening exponents determined from the tensile coupon tests were compared with the calculation formulae given in EN 1993-1-4+A1 [19] and the expressions proposed by Arrayago et al. [31]. The results are summarised in Table 4, in which $n_{\text {Test }}$ and $m_{\text {Test }}$ are the experimentally determined exponents and $n_{\text {Pre }}$ and $m_{\text {Pre }}$ are the computed values by using the corresponding expressions given in Table 4. It can be seen that the formula in Annex C of EN 1993-1-4+A1 [19] leads to lower results for the first strain hardening exponent $n$, with mean ratios of test to predicted results ( $n_{\text {Test }} / n_{\text {Pre }}$ ) equal to 1.25 and 1.28 for austenitic and duplex grades, respectively. While the expression proposed by Arrayago et al. [31] gives more accurate results of the exponent $n$ by using the $0.05 \%$ proof stress instead of the $0.01 \%$ proof stress, where the mean values of $n_{\text {Test }} / n_{\text {Pre }}$ are 0.98 and 1.02 for austenitic and duplex grades, respectively. Moreover, it is also revealed that the revised formula proposed by Arrayago et al. [31] provides closer results for the second strain hardening exponent $m$ for austenitic grade EN $1.4301\left(m_{\text {Test }} / m_{\text {Pre }}=0.94\right)$ than those from EN 1993-1-4+A1 [19] $\left(m_{\text {Test }} / m_{\text {Pre }}=0.84\right)$, though a slightly lower ratio is obtained for duplex grade EN 1.4462 with a mean ratio $m_{\text {Test }} / m_{\text {Pre }}$ of 1.26 .

Table 4

Assessment of the calculation expressions for strain hardening exponents

\begin{tabular}{|c|c|c|c|c|c|}
\hline \multirow{3}{*}{\multicolumn{2}{|c|}{ Grade }} & \multicolumn{2}{|c|}{$n_{\text {Test }} / n_{\text {Pre }}$} & \multicolumn{2}{|c|}{$m_{\text {Test }} / m_{\text {Pre }}$} \\
\hline & & EN 1993-1-4+A1 [19] & Arrayago et al. [31] & $\begin{array}{c}\text { EN 1993-1-4+A1 } \\
{[19]}\end{array}$ & Arrayago et al. [31] \\
\hline & & $n=\ln (20) / \ln \left(\sigma_{0.2} / \sigma_{0.01}\right)$ & $n=\ln (4) / \ln \left(\sigma_{0.2} / \sigma_{0.05}\right)$ & $m=1+3.5 \sigma_{0.2} / \sigma_{\mathrm{u}}$ & $m=1+2.8 \sigma_{0.2} / \sigma_{\mathrm{u}}$ \\
\hline & Mean & 1.25 & 0.98 & 0.84 & 0.94 \\
\hline
\end{tabular}


Austenitic

EN 1.430

$\mathrm{COV}$

0.16

0.16

0.12

0.12

\begin{tabular}{cccccc} 
Duplex & Mean & 1.28 & 1.02 & 1.08 & 1.26 \\
EN 1.4462 & COV & 0.10 & 0.04 & 0.08 & 0.07 \\
\hline
\end{tabular}

\subsection{Plate girder tests}

The experimental setup for plate girder tests is shown in Fig. 7, which was successfully applied in the previous studies on shear behaviour of stainless steel girders [26-27]. Each plate girder specimen was tested under three-point bending condition, resulting in a combination of relatively high shear force and high bending moment within the interior web panels. The concentrated load at mid-span was applied through a rigid bearing block with a width of 100 $\mathrm{mm}$. The simply supported conditions were achieved by mounting the specimens on two steel bearings including the roller support at one end and the pin support at the other end. Both ends of the specimens were clamped by steel frames designed with moderate height, at which the lateral displacements and the rotation about longitudinal axis were restrained. Meanwhile, another two lateral supports were placed adjacent to the interior web panels to prevent the plate girder specimens from lateral-torsional buckling. It should be noted that a small gap was kept between the lateral supports/clamping frames and the contact points of specimen, and a thin layer of lubricating oil was also applied on each contact surface to further reduce the possible friction.

The employed instrumentation configuration for the plate girder tests is illustrated in Fig. 8, in which a total of sixteen triaxial strain gauges, twenty uniaxial strain gauges and seven laser displacement sensors (LDSs) are included. For each side of an interior web panel, three triaxial strain gauges were attached along the centreline to determine the critical buckling strength, and another triaxial strain gauge was affixed at the upper corner to monitor the strain development. Moreover, three uniaxial strain gauges were placed on the cross-section at a distance of $a / 5$ ( $a$ is the width of web panel) from the mid-span transverse stiffener, and another two gauges located on the upper flange at the same cross-section. The vertical displacements at mid-span and both end supports were measured using three LDSs, whist four other LDSs were symmetrically installed at the centre of the interior web panels to capture the out-of-plane deformations.

The plate girder tests were conducted by using a $5000 \mathrm{kN}$ capacity hydraulic testing machine. Each specimen was initially loaded at a rate of $0.2 \mathrm{kN} / \mathrm{s}$ until the out-of-plane deformation in interior web panels became noticeable, and a displacement control with a constant rate of $0.01 \mathrm{~mm} / \mathrm{s}$ was activated afterwards. The testing process was then continued by capturing the post-peak behaviour and the failing path of the plate girder specimens, before excessive deflection or severe drop in load was observed.

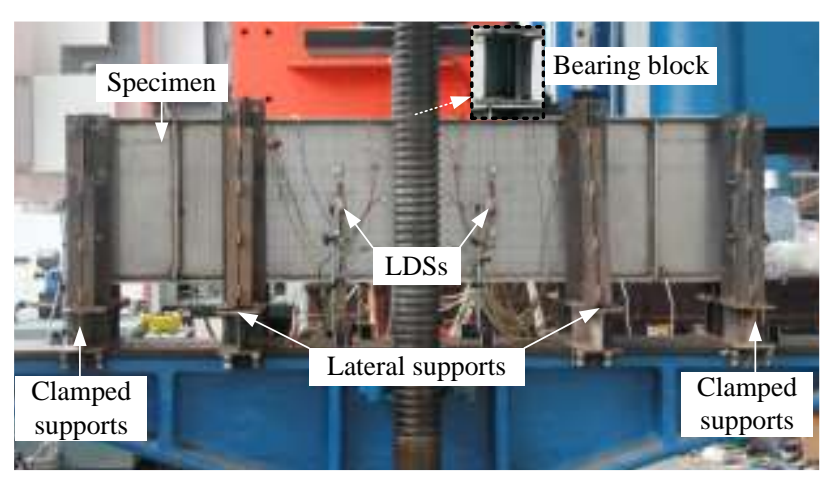

(a) Photo

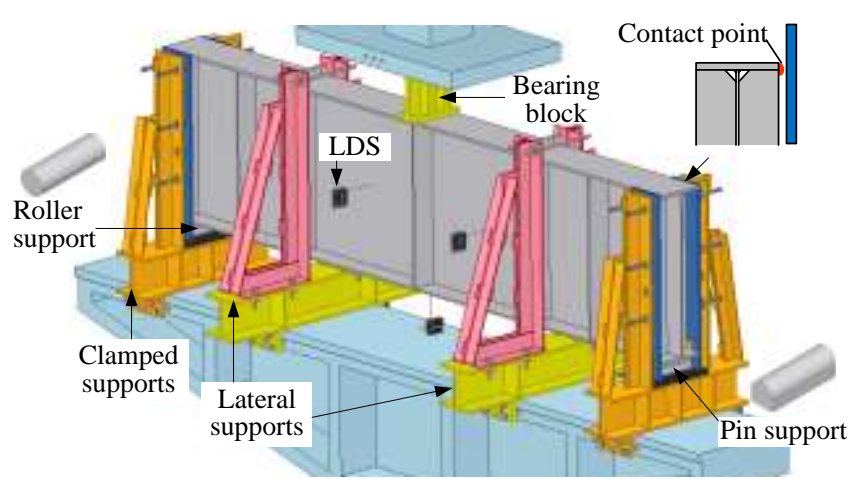

(b) Schematic drawing

Fig. 7. Experimental setup for plate girders under combined bending and shear 


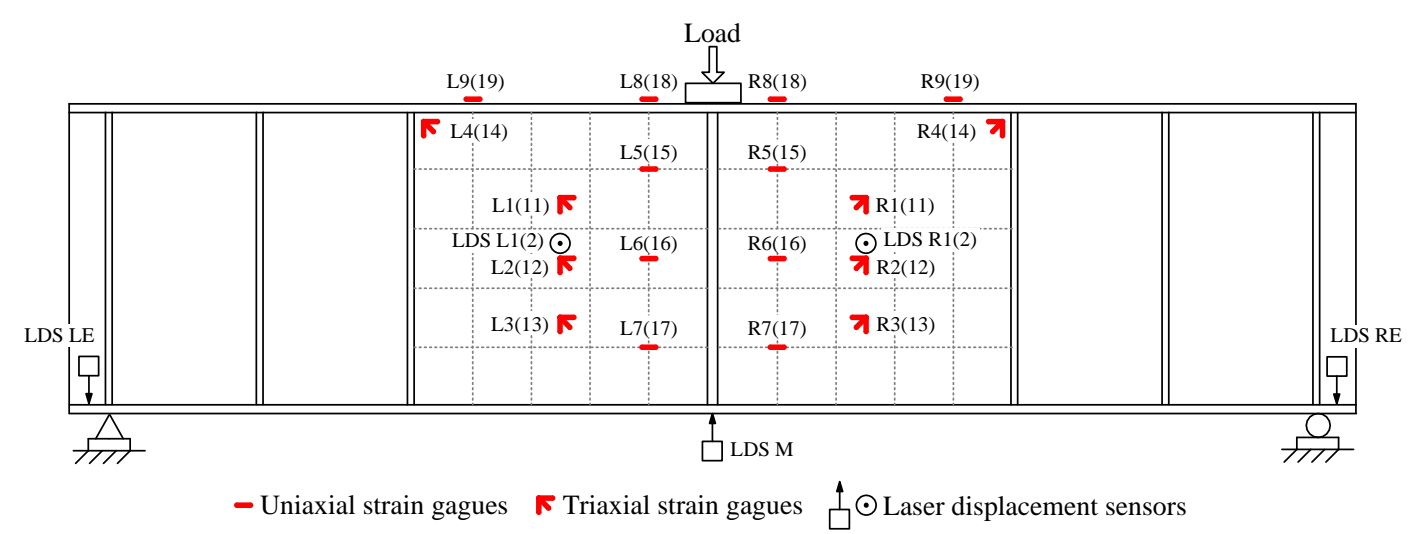

Fig. 8. Instrumentation configuration for plate girder tests

\section{Analysis of experimental results}

\subsection{Collapse behaviour}

All six tested specimens failed by a combination of bending and shear buckling mode, and four of which had noticeable buckled shapes in the interior web panels, while the other two exhibited local flange buckling combined with web buckling. The deformed shapes of tested specimens are displayed in Fig. 9. The interaction failure mode can be identified from the appearance of shear buckling in the web panel and local compression buckling in the web and upper flange. The formation of plastic hinges in the upper flange is also observed for all tested plate girders, yet at different locations. For two specimens VM-304-300ad1 and VM-2205-300ad1, a well-defined tension field is found to be developed in the interior web panels with apparent rotations of the plastic hinges in the upper flange. While the other four specimens - VM-304-300ad1.5, VM-304-600ad1, VM-2205-300ad1.5 and VM-2205-600ad1 exhibit less inclined tension field, but both the compression flange and web display much more noticeable local plate buckling, indicating the bending and shear interaction effect. Despite the different geometric shapes adopted in this study, additional stainless steel plate girder tests are still expected to further examine the possible size effect and to cover a wider range of cross-sectional properties and web aspect ratios.

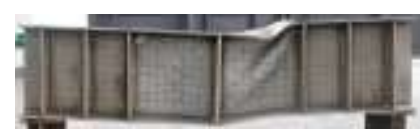

VM-304-300ad1

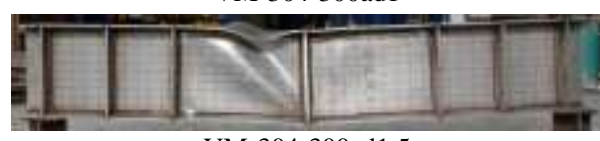

VM-304-300ad1.5

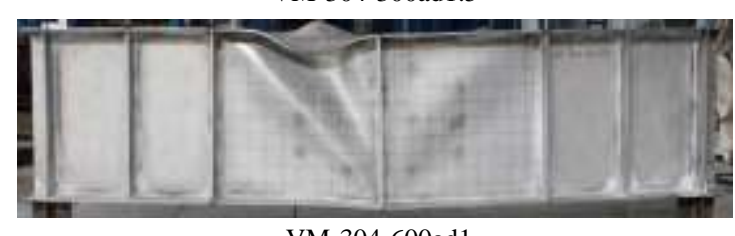

VM-304-600ad1

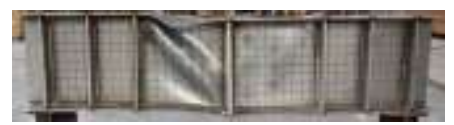

VM-2205-300ad1

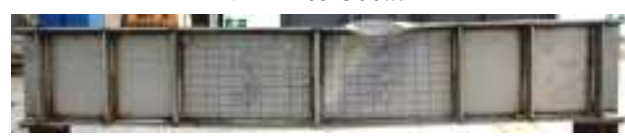

VM-2205-300ad1.5

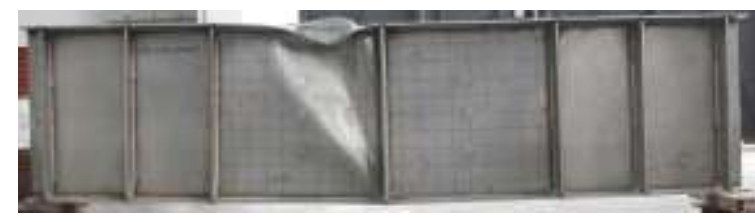

VM-2205-600ad1

(b) Duplex grade EN 1.4462

(a) Austenitic grade EN 1.4301

Fig. 9. Deformed shapes of the tested plate girders

The shear force $V$ (taken as half of the applied load) versus mid-span vertical displacement curves of all plate girder specimens are presented in Fig. 10. The curves of specimens with the same aspect ratios $a / h_{\mathrm{w}}$ are consistent in the initial stiffness, yet a decreased gradient, revealing a reduction of flexural stiffness, was found for specimens with higher web aspect ratios. Meanwhile, the normalised shear force $V / V_{\mathrm{pl}}$ versus mid-span vertical displacement curves 
are also shown in Fig. 11, where the plastic shear resistance $V_{\mathrm{pl}}$ is taken as $h_{\mathrm{w}} t_{\mathrm{w}} \sigma_{0.2} / \sqrt{3}$. In this case, the curves of specimens with bending and shear interaction failure modes are consistent in the initial stiffness with each other, such as VM-304-300ad1.5 with VM-304-600ad1 or VM-2205-300ad1.5 with VM-2205-600ad1, while an increased stiffness was found for specimens that exhibit shear buckling failure modes - VM-304-300ad1 and VM-2205-300ad1. All specimens experienced high level of ductility at failure and had a flat plateau during the post-peak region. The experimentally obtained values of the ultimate shear resistances $V_{\mathrm{u}}$, the ultimate bending moment $M_{\mathrm{u}, \mathrm{Max}}\left(=2 a \times V_{\mathrm{u}}\right)$ and the normalised shear force values $\left(V / V_{\mathrm{pl}}\right)$ are listed in Table 5. It is shown that the duplex plate girders display higher ultimate resistances than their austenitic counterparts due to the higher nominal yield strength $\left(\sigma_{0.2}\right)$, while the duplex plate girders demonstrate lower values of $V / V_{\mathrm{pl}}$ that can be attributed to the less considerable strain hardening capacity of the material yet the much higher nominal yield strength used in the normalisation procedure.

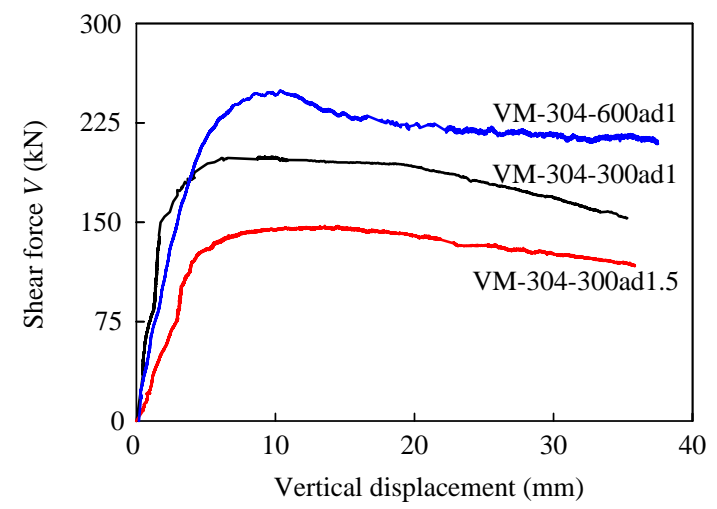

(a) Austenitic grade EN 1.4301

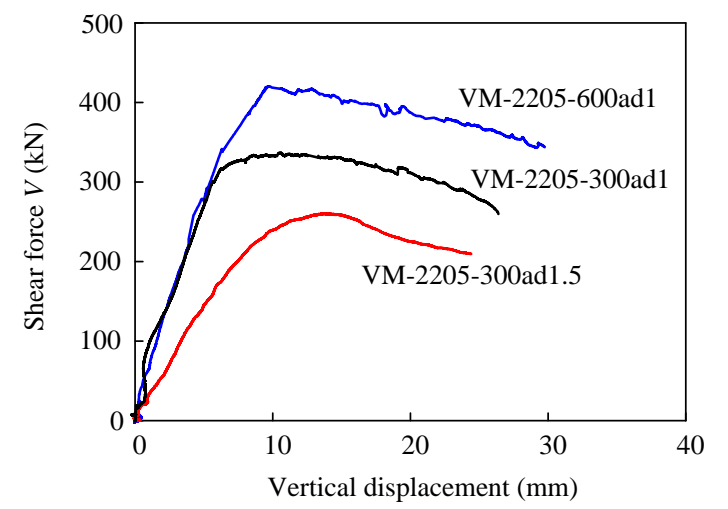

(b) Duplex grade EN 1.4462

Fig. 10. Shear force versus mid-span vertical displacement curves

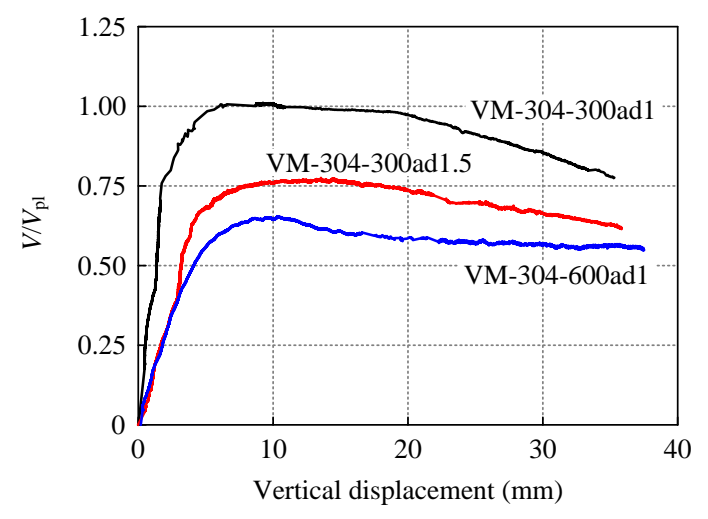

(a) Austenitic grade EN 1.4301

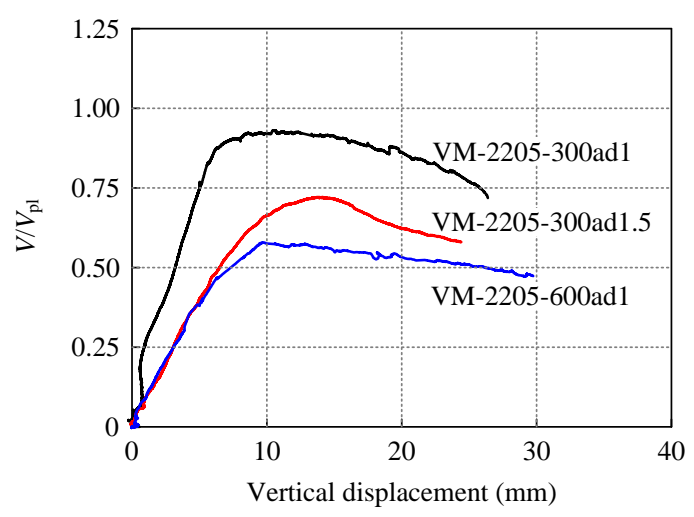

(b) Duplex grade EN 1.4462

Fig. 11. Normalised shear force $V / V_{\mathrm{pl}}$ versus mid-span vertical displacement curves

Table 5

Summary of the experimental results

\begin{tabular}{|c|c|c|c|c|c|c|c|c|c|}
\hline \multirow[b]{2}{*}{ Specimens } & \multirow[b]{2}{*}{$\lambda_{\mathrm{w}}$} & \multirow[b]{2}{*}{$V_{\mathrm{pl}}(\mathrm{kN})$} & \multicolumn{3}{|c|}{ Ultimate resistance } & \multicolumn{2}{|c|}{ Critical buckling strength } & \multicolumn{2}{|c|}{ Postbuckling capacity } \\
\hline & & & $V_{\mathrm{u}}(\mathrm{kN})$ & $V_{\mathrm{u}} / V_{\mathrm{pl}}$ & $\begin{array}{l}M_{\mathrm{u}, \mathrm{Max}} \\
(\mathrm{kN} \cdot \mathrm{m})\end{array}$ & $V_{\mathrm{cr}}(\mathrm{kN})$ & $V_{\mathrm{cr}} / V_{\mathrm{u}}$ & $\begin{array}{c}V_{\text {post }}=V_{\mathrm{u}}-V_{\text {cr }} \\
(\mathrm{kN})\end{array}$ & $V_{\text {post }} / V_{\mathrm{u}}$ \\
\hline VM-304-300ad1 & 0.73 & 197.4 & 199.7 & 1.01 & 119.5 & 161.2 & 0.81 & 38.5 & 0.19 \\
\hline VM-304-300ad1.5 & 0.90 & 190.0 & 147.3 & 0.78 & 132.2 & 129.8 & 0.88 & 17.5 & 0.12 \\
\hline VM-304-600ad1 & 1.58 & 381.4 & 249.7 & 0.65 & 299.3 & 51.4 & 0.21 & 198.3 & 0.79 \\
\hline VM-2205-300ad1 & 1.03 & 361.7 & 336.6 & 0.93 & 201.3 & 265.8 & 0.79 & 70.8 & 0.21 \\
\hline VM-2205-300ad1.5 & 1.17 & 361.2 & 260.7 & 0.72 & 234.1 & 220.7 & 0.85 & 40.0 & 0.15 \\
\hline
\end{tabular}




\subsection{Critical buckling behaviour}

Two typical specimens - VM-2205-300ad1.5 and VM-2205-600ad1 with apparent bending and shear interaction failure mode were analysed in this sub-section. The strain reversal method [32-33], which was successfully applied for determining the critical shear buckling strength of stainless steel plate girders [26], was adopted herein to explore the critical buckling behaviour of the interior web panels. Specifically, the strength corresponding to the reversal point from the shear force versus principal surface strain relationship can be taken as the critical bucking strength, beyond which an immediate drop in the principal compressive strain (PC) on the convex side of the buckle is noted. By using the obtained strains of the interior web panels recorded by two paired triaxial strain gauges, the principal surface strains, including the principal compressive strain (PC) and the principal tensile strain (PT) were separately calculated for each side. Meanwhile, the principal membrane strain can also be obtained by calculating the mean values of the strains on both sides of web panel in three directions $\left(0^{\circ}, 45^{\circ}\right.$ and $\left.90^{\circ}\right)$ of the paired triaxial strain gauges.

The shear force versus principal surface strain curves for specimen VM-2205-300ad1.5 are plotted in Fig. 12, and the evolution of the principal membrane strains along the centreline of the interior web panel is illustrated in Fig. 13. It has to be noted that the points of critical buckling shown in Fig. 13 coincide to the reversal points of principal surface strain curves presented in Fig. 12. It can also be seen that the shear forces corresponding to the strain reversal points for the three different locations appear to be close to each other, and the surface strains are well below the material yield strain $\varepsilon_{y}$ listed in Table 2. However, the evolution of principal membrane strains revealed by Fig. 13 indicates the apparent interaction effect of combined bending moment and shear force within the interior web panel, where the local buckling at the upper point close to the web/top flange junction (Fig. 13 (a)) occurs at considerably higher compressive strain but much lower tensile strain than that of the lower point close to the web/top flange junction (Fig. 13 (b)). The principal tensile strains drop sharply subsequent to the achievement of the ultimate resistance. Moreover, the shear force versus surface strains curves from the gauges located at the cross-section in the vicinity of the mid-span transverse stiffeners are displayed in Fig. 14, from which the reversal point at the upper point of the web panel (see Fig. 14 (a)) is observed to be slightly higher than those obtained from curves shown in Fig. 12. In addition, it is interesting to note that the neutral axis of web panel is in a state of pure shear prior to the onset of local buckling, as illustrated by Fig. 13 (b), where the principal tensile strain is approximately equal to the compressive value. Besides, the corresponding longitudinal membrane strains shown in Fig. 14 (b) are negligibly small.

For the plate girder VM-2205-600ad1 with more slender interior web panels $\left(h_{\mathrm{w}} / t_{\mathrm{w}}=153.36, \lambda_{\mathrm{w}}=2.07\right)$, the obtained experimental results, including the corresponding developments of principal surface strains, principal membrane strains and longitudinal strains are presented in Fig. 15 - Fig. 17. Unlike the specimen VM-2205-300ad1.5, the initial local buckling occurred at the upper point (see Fig. 15 (a), which is much earlier than that at the central point (see Fig. 15 (b)). This can be attributed to the fact that the upper point close to the web/top flange junction was subjected to a combination of compression and shear stresses, while the central point was under pure shear, as revealed by Fig. 16 (a) and (b), respectively. It is therefore concluded that the shear stresses plus the compressive stresses generated by the bending moment can lead to premature local buckling in the web panel. Moreover, much less strain development from the interior web panel of the specimen VM-2205-600ad1 (Fig. 16) can be found for both critical buckling and ultimate states when compared with the specimen VM-2205-300ad1.5 (Fig. 13).

It is important to note that though slightly lower reversal points can be found from the principal compressive strain curves at the lower points of the interior web panels (as shown in Fig. 12 (c) and Fig. 15 (c)), these abnormal points resulted by the tensile stresses were not coincided with the onset of local buckling phenomenon as indicated by the testing process and the deformed shapes in Fig. 9. Therefore, the shear force associated with the critical buckling of the upper point of the interior web panel, as illustrated in Fig. 12 (a) and Fig. 15 (a), was taken as the critical bucking strength $V_{\text {cr }}$ for the specimen, and the obtained results are listed in Table 5. It is shown that the critical buckling 
strengths of the web panels $V_{\text {cr }}$ are significantly lower than the ultimate resistances $V_{\mathrm{u}}$, especially for specimens VM304-600ad1 and VM-2205-600ad1, where the values of $V_{\mathrm{cr}} / V_{\mathrm{u}}$ equal to 0.21 and 0.34 , respectively, indicating a considerable development of postbuckling strength $V_{\text {post. }}$. It is also revealed that the duplex plate girders display much higher critical buckling strengths $V_{\text {cr }}$ and postbuckling capacities $V_{\text {post }}$ than the austenitic counterparts, which can be attributed to their higher material yield strength. Further numerical and analytical analysis would still be needed to investigate the critical buckling behaviour of web panels described herein.

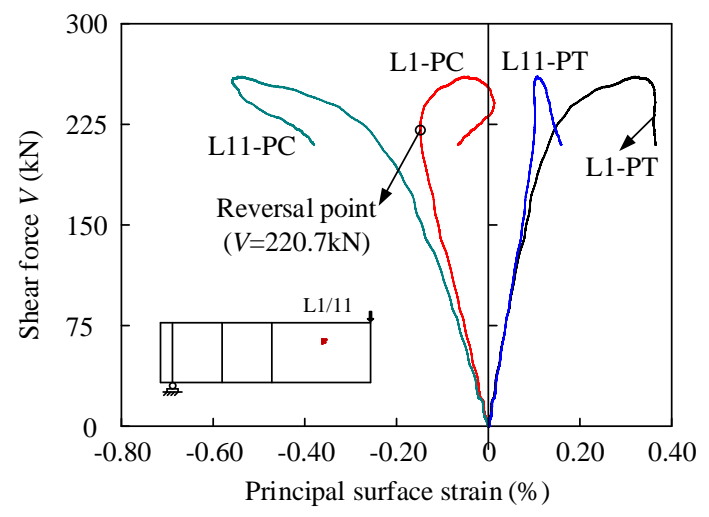

(a) At upper point

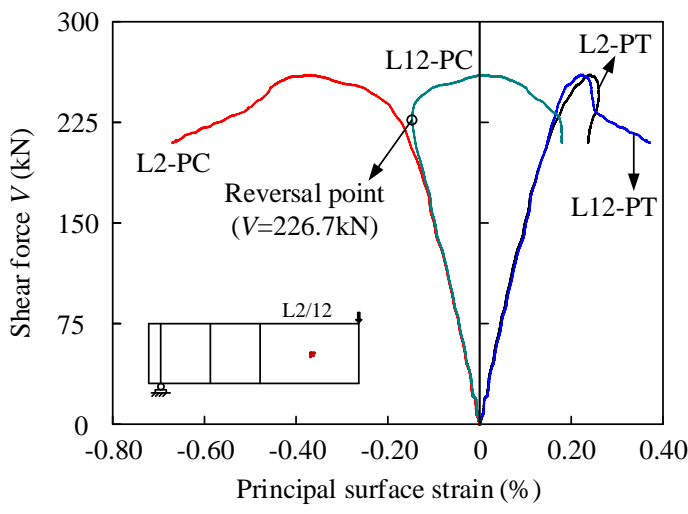

(b) At central point

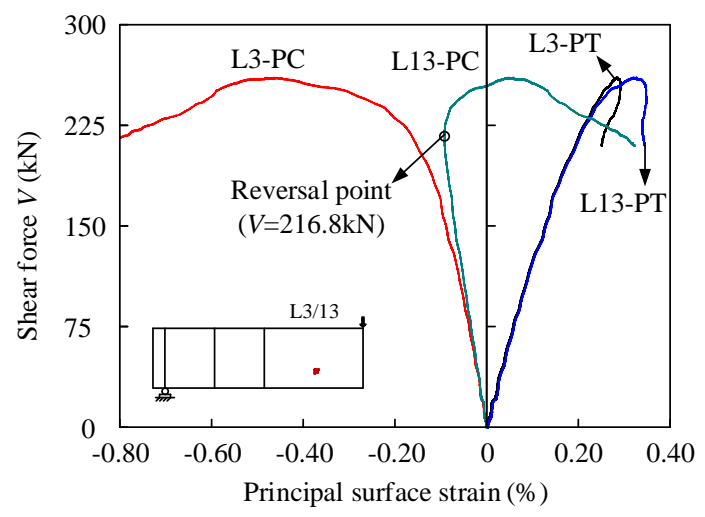

(c) At lower point

Fig. 12. Shear force versus principal surface strain curves for specimen VM-2205-300ad1.5

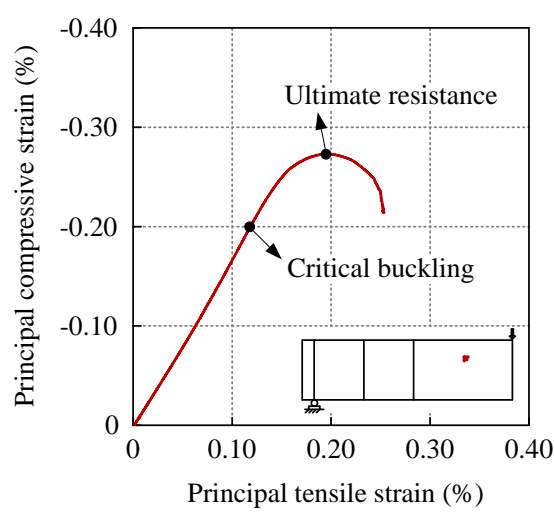

(a) At upper point

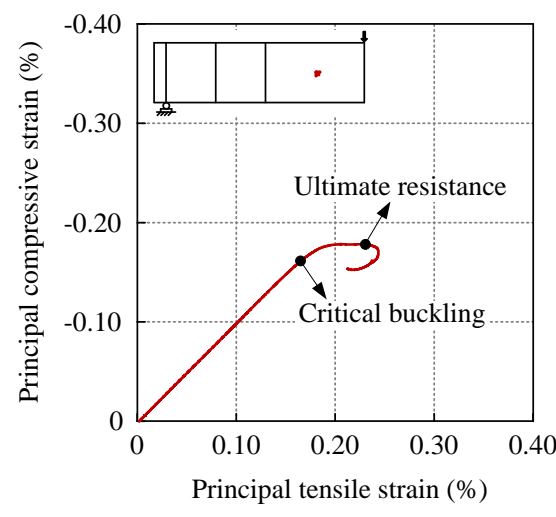

(b) At central point

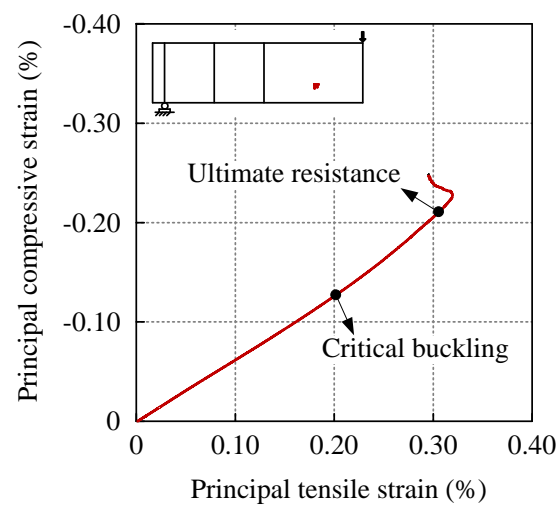

(c) At lower point

Fig. 13. Evolution of principal membrane strains in interior web panel (specimen VM-2205-300ad1.5) 


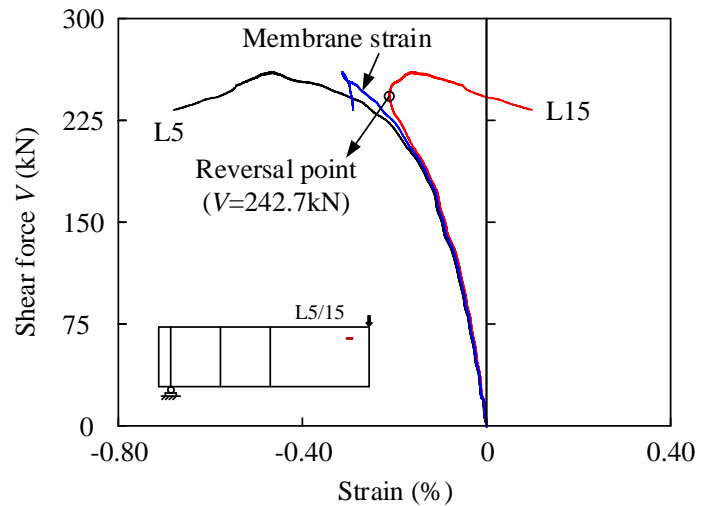

(a) At upper point

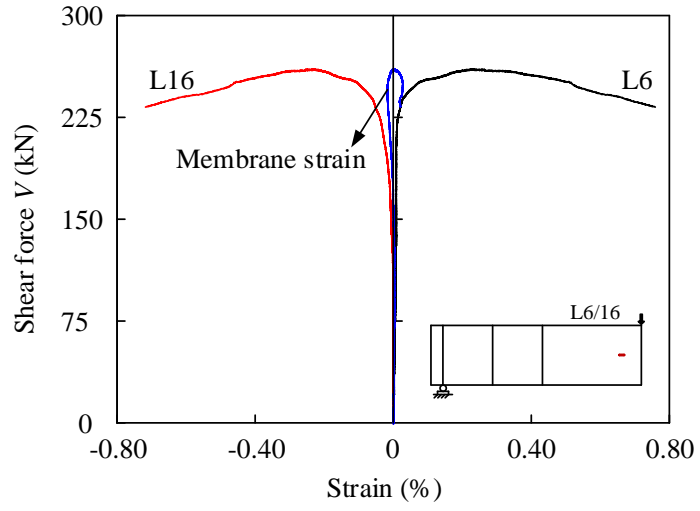

(b) At central point

Fig. 14. Evolution of longitudinal strains in web panel (specimen VM-2205-300ad1.5)

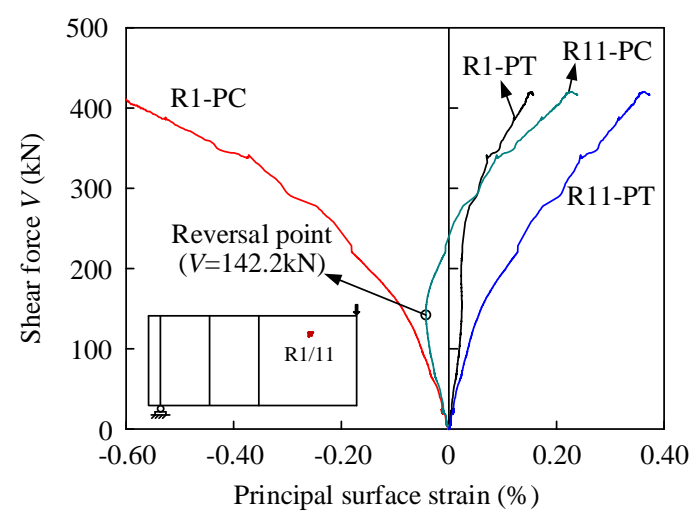

(a) At upper point

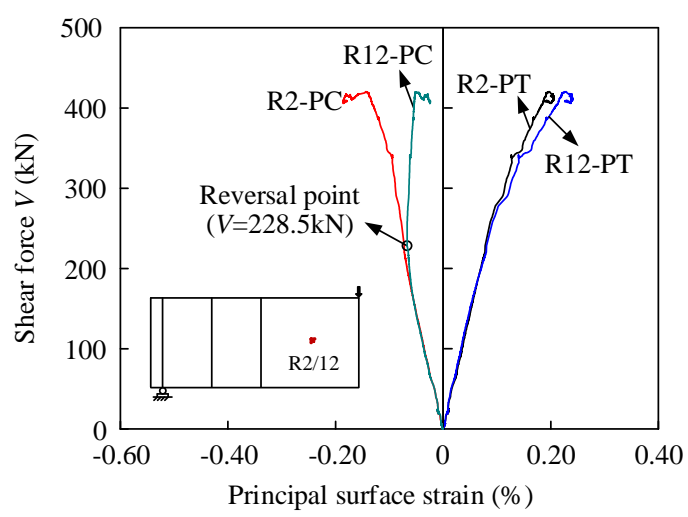

(b) At central point

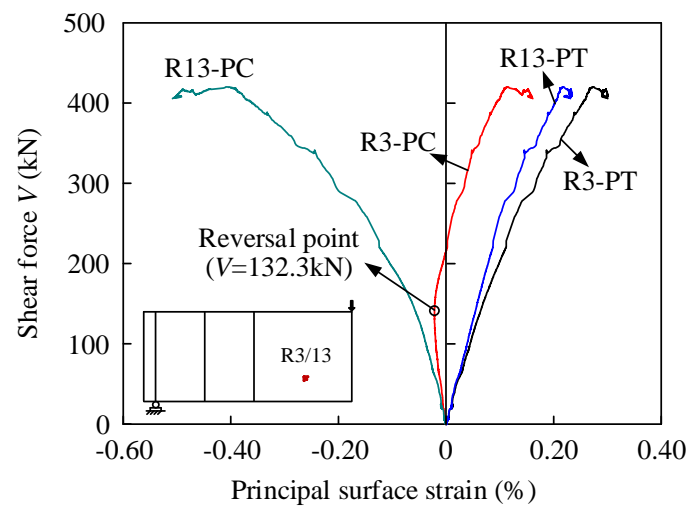

(c) At lower point

Fig. 15. Shear force versus principal surface strain curves for specimen VM-2205-600ad1 


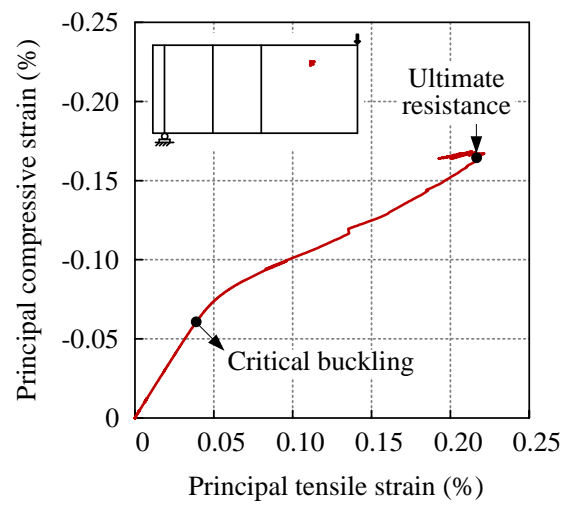

(a) At upper point

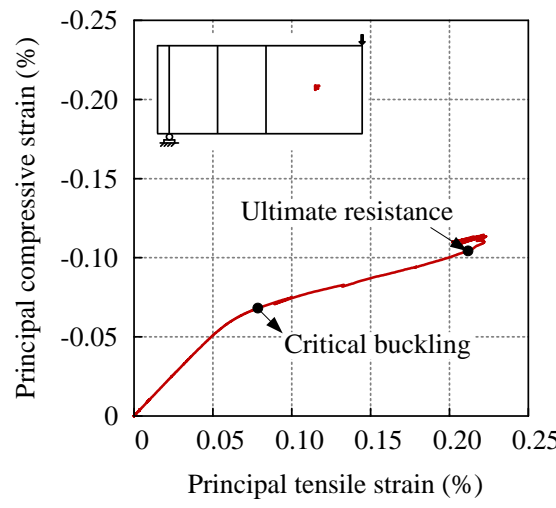

(b) At central point

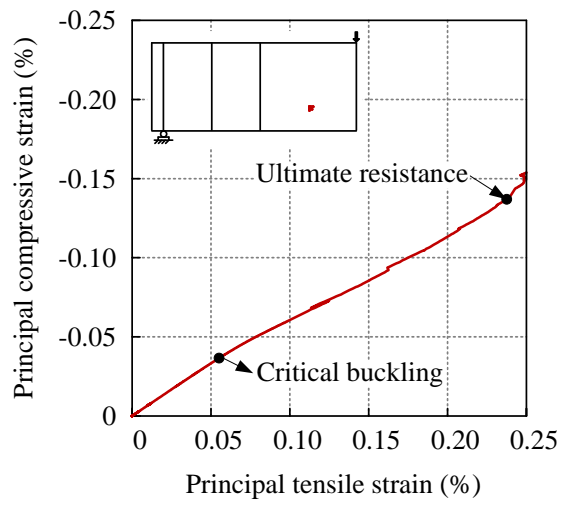

(c) At lower point

Fig. 16. Evolution of principal membrane strains in web panel (specimen VM-2205-600ad1)

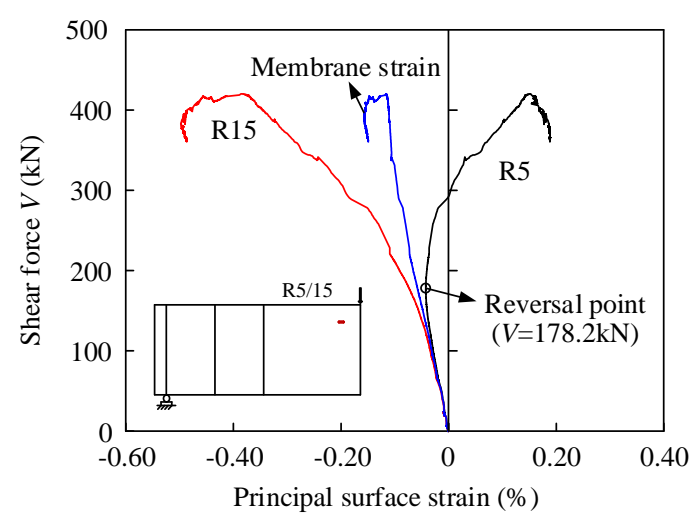

(a) At upper point

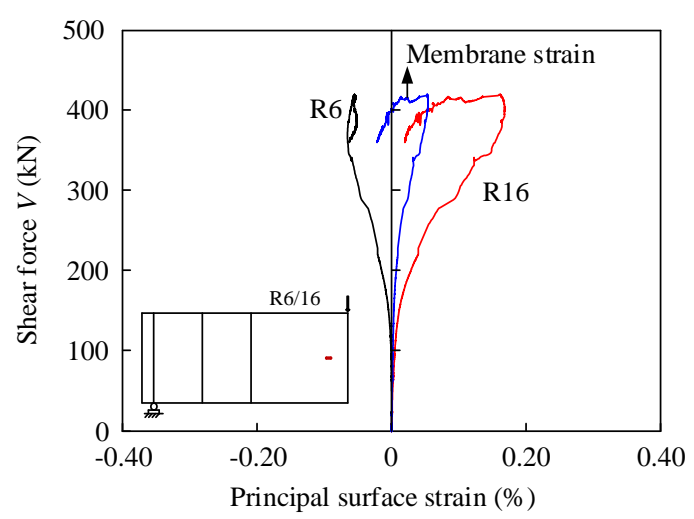

(b) At central point

Fig. 17. Evolution of longitudinal strains in web panel (specimen VM-2205-600ad1)

\section{Comparison of test results with $\mathrm{M}-\mathrm{V}$ interaction design curves}

\subsection{General}

The obtained ultimate resistances are further used to assess the applicability of the existing M-V interaction design methods in EN 1993-1-5 [2], GB 50017-2017 [3], ANSI/AISC 360-16 [4] and SEI/ASCE 8-02 [20], and the design proposal presented by Jáger et al. [10]. In the first step, the location of the cross-section with considerable bending and shear interaction effect is to be identified. For a simply supported plate girder subjected to a concentrated load at midspan, the absolute value of the shear force $(V)$ remains constant along the full span length, yet the bending moment reaches the peak value $\left(M_{\max }\right)$ at mid-span, as illustrated in Fig. 18. However, the augmentation of paired transverse stiffeners at loading point would provide additional restraints for the web panel and flanges in the vicinity of mid-span. Hence the local buckling of web panel cannot occur at mid-span, though the combination of highest bending stress and shear stress is achieved. Moreover, the existing studies [1,7,9] have indicated that the moment gradient has a positive effect on the moment-shear interaction resistance. Therefore, the $\mathrm{M}-\mathrm{V}$ interaction checking location has been taken as the cross-section located at a distance of one half of the web depth from the mid-span in this study, which is the same with that prescribed in EN 1993-1-5 [2]. The corresponding resistances that were experimentally determined at the interaction checking cross-section are given in Tables 6 and 7 , where $M_{\mathrm{u}}$ is equal to $\left(2 a-h_{\mathrm{w}} / 2\right) V_{\mathrm{u}}$.

The assessment is represented by the ratio of the test to predicted capacities $R_{\mathrm{u}, \text { Test }} / R_{\mathrm{u}, \mathrm{pre}}$, as defined in Fig. 19 , where $R_{\mathrm{u}, \text { Test }}$ is the distance from the origin of the $\mathrm{M}-\mathrm{V}$ interaction diagram to the test data point, while $R_{\mathrm{u}, \mathrm{pre}}$ is the distance from the origin to the intersection with the $\mathrm{M}-\mathrm{V}$ interaction curve. A value of $R_{\mathrm{u}, \text { Test }} / R_{\mathrm{u}, \mathrm{pre}}$ greater than 1.0 indicates that 
the test data point lies outside the interaction curve, which means the prediction is on the safe side. It should be noted that all comparisons conducted in this sub-section are based on the previously measured material and geometric properties, and all partial factors have been set equal to unity.

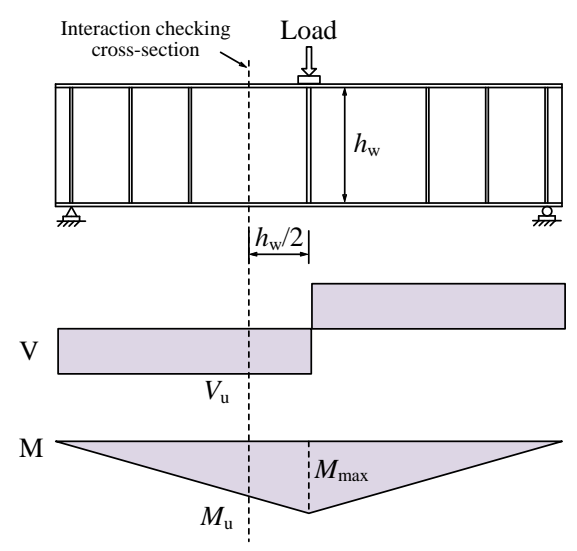

Fig. 18. M-V Interaction checking location

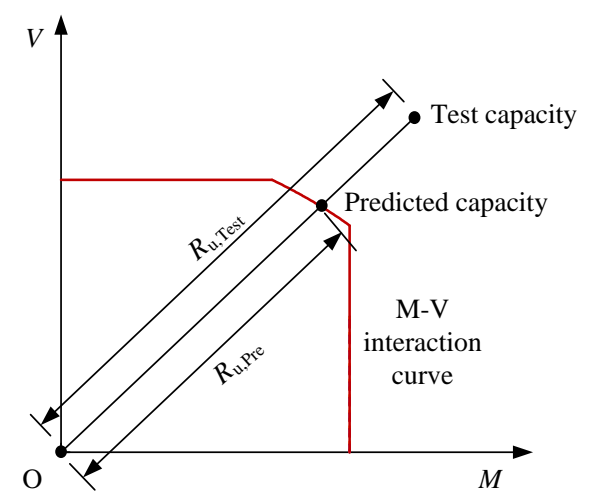

Fig. 19. Definition of parameters $R_{\mathrm{u}, \text { Test }}$ and $R_{\mathrm{u}, \text { Pre }}$

\subsection{Design curve in EN 1993-1-5 and proposal of Jáger et al.}

The current European code EN 1993-1-5 [2] for plated structural elements employs the modified M-V interaction curve based on Basler's expression [1]. It is specified that the bending and shear interaction effect should be taken into account when the bending moment is higher than the bending capacity of the flanges $M_{\mathrm{f}}$ or the shear force exceeds half of the ultimate shear resistance of the web panel $V_{\mathrm{bw}}$. The interaction expression is given by Eq. (1) and is presented in Fig. 20.

$$
\frac{M}{M_{\mathrm{pl}}}+\left(1-\frac{M_{\mathrm{f}}}{M_{\mathrm{pl}}}\right)\left(\frac{2 V}{V_{\mathrm{bw}}}-1\right)^{2} \leq 1.0 \quad \text { for } M \geq M_{\mathrm{f}}
$$

where $M_{\mathrm{pl}}$ is the plastic bending capacity of the effective cross-section; $M$ and $V$ are the applied bending moment and shear force, respectively. Meanwhile, the interaction curve is also limited to the elastic bending capacity of the effective cross-section $M_{\text {eff, }}$ wherein the effective cross-sectional properties can be calculated by using the effective width approach. The ultimate shear resistance $V_{\mathrm{bw}}$ is determined on the basis on the rotated stress field model, in which the shear resistance contribution from the flange $V_{\text {bf }}$ is taken into account when it is not fully mobilised in resisting bending moment.

A modified form of M-V interaction expression for transversely stiffened carbon steel plate girders was proposed by Jáger et al. [10], which was revised from the formula presented by Sinur and Beg [9] for longitudinally stiffened 
plate girders. Compared to the expression in EN 1993-1-5, the elastic bending capacity $M_{\text {eff }}$ was used to replace the plastic bending capacity $M_{\mathrm{pl}}$ in Eq. (2), whist the exponent value of 2 was replaced by the parameter $\kappa$ defined by Eq. (3) as recommended by Jáger et al. [10].

$$
\begin{gathered}
\frac{M}{M_{\text {eff }}}+\left(1-\frac{M_{\mathrm{f}}}{M_{\text {eff }}}\right)\left(\frac{2 V}{V_{\mathrm{bw}}}-1\right)^{\kappa} \leq 1.0 \text { for } M \geq M_{\mathrm{f}} \\
\kappa=\left(\frac{M_{\mathrm{f}}}{M_{\text {eff }}}+0.2\right)^{15}+1
\end{gathered}
$$

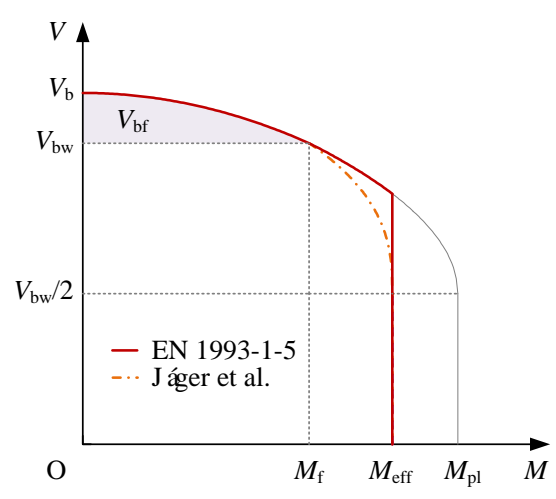

Fig. 20. M-V Interaction curves in EN 1993-1-5 [2] and Jáger et al. [10]

Note that these two M-V interaction curves depend upon the cross-sectional geometry, hence separate design curves for the tested plate girders are depicted in Fig. 21, and the comparison results are summarised in Table 5. The crosssectional capacities given in Table 5 were computed by referring to the provisions set in the current EN 1993-1-4+A1 for stainless steel structures [19], and these capacities were used in drawing the M-V interaction curve of EN 1993-15 and Jáger et al. in Fig. 21. The shear resistances of web panels were calculated by assuming rigid end post conditions, which were assured by the use of additional transverse stiffeners close to both ends of the tested specimens, and the bending capacities were determined by using the effective width approach.

For the four tested specimens with $a / h_{\mathrm{w}}=1.0$ (labeled with -ad1), where the ratio of shear force to bending moment $V_{\mathrm{u}} / M_{\mathrm{u}}>V_{\mathrm{bw}} / M_{\mathrm{f}}$, the shear design method in EN 1994-1-4+A1 for plate girders designed with rigid end post, was found to yield acceptable strength predictions for the tested interior web panels, yet lead to a slight degree of conservatism for plate girders made of duplex grade EN 1.4462. Regarding the two specimens with $a / h_{\mathrm{w}}=1.5$ and $V_{\mathrm{u}} / M_{\mathrm{u}}<V_{\mathrm{bw}} / M_{\mathrm{f}}$, the comparison has demonstrated the M-V interaction curves in EN 1993-1-5 [2], primarily given for carbon steel plate girders, are capable of providing safe predictions for the two tested stainless steel plate girders, with the ratios of test to predicted capacities $R_{\mathrm{u}, \text { Test }} / R_{\mathrm{u}, \mathrm{pre}}$ of 1.05 . The obtained mean ratio of test to predicted capacities $R_{\mathrm{u}, \text { Test }} / R_{\mathrm{u}, \mathrm{pre}}$ is 1.04 , with a negligible Coefficient of Variation (COV) of 0.02 for the austenitic plate girders, while for the duplex specimens, the corresponding mean value is 1.07 with a COV equal to 0.03 . Moreover, similar predictions are obtained regarding the $\mathrm{M}-\mathrm{V}$ interaction formulae proposed by Jáger et al. [10]. 

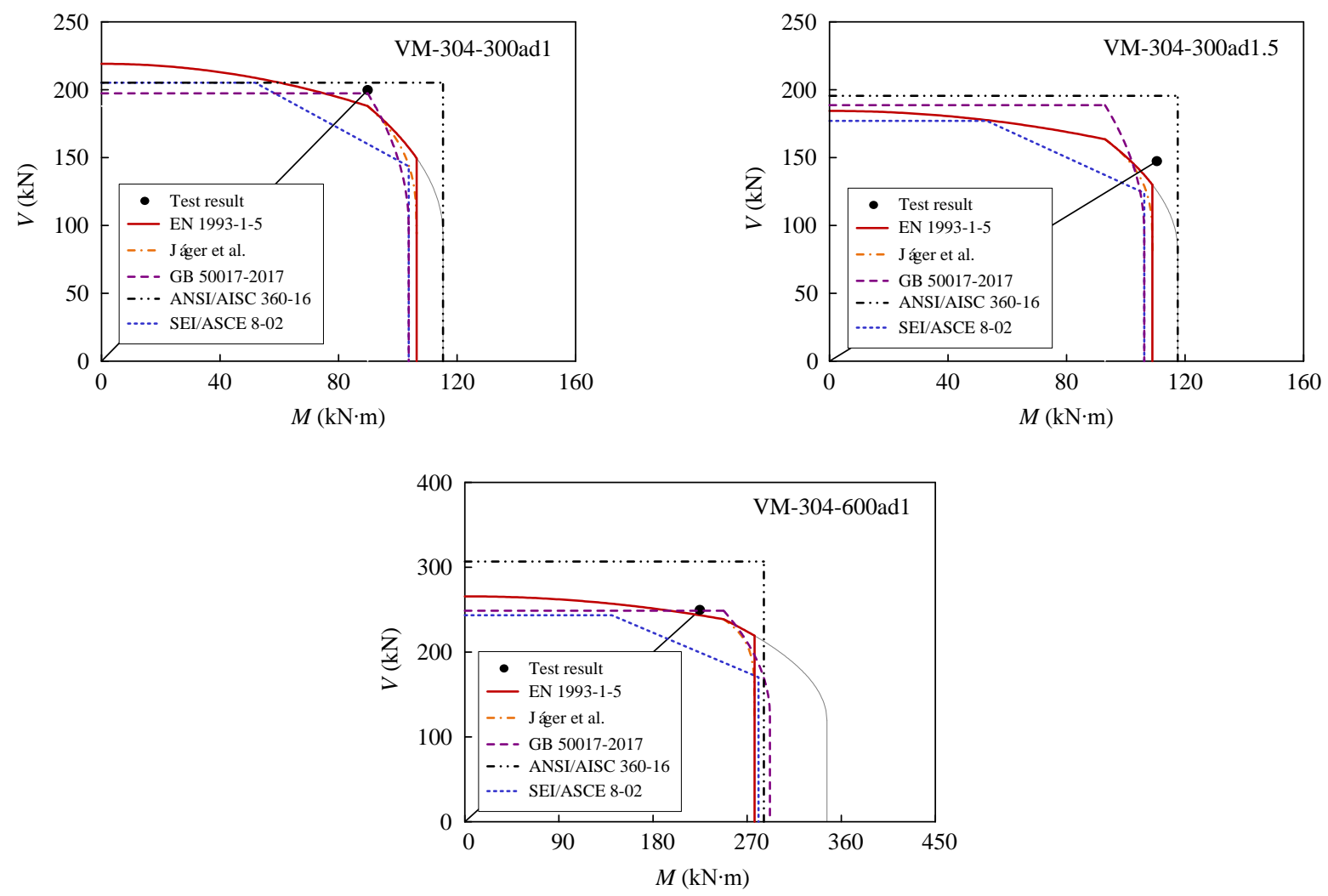

(a) Austenitic grade EN 1.4301
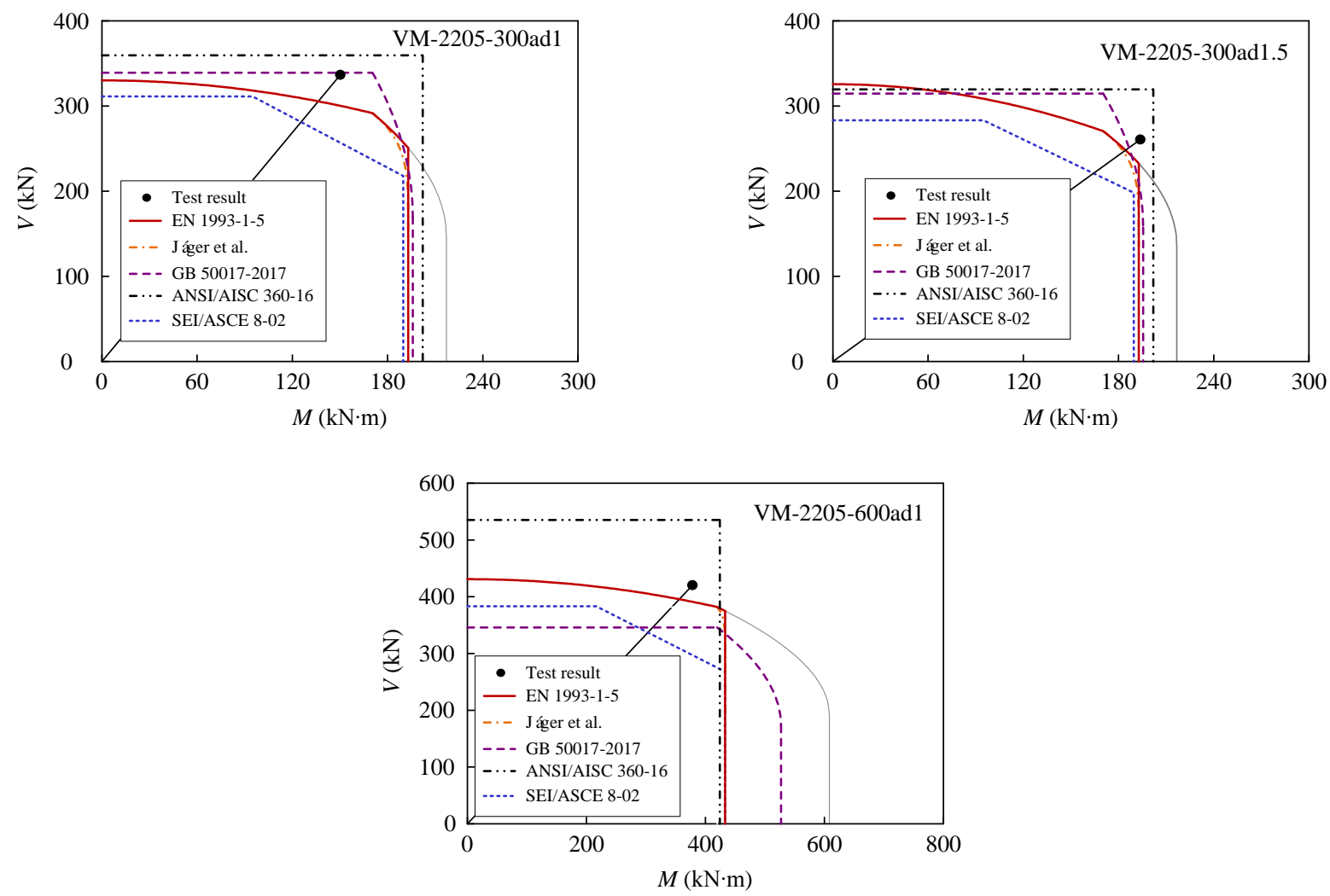

(b) Duplex grade EN 1.4462

Fig. 21. Comparison of test results with current design methods 
Table 6

Comparison of test results with M-V curves from EN 1993-1-5 [2] and Jáger et al. [10]

\begin{tabular}{|c|c|c|c|c|c|c|c|c|c|}
\hline \multirow[b]{2}{*}{ Specimens } & \multicolumn{2}{|c|}{ Test results } & \multicolumn{5}{|c|}{ Cross-sectional capacities } & \multirow{2}{*}{$\frac{\text { EN 1993-1-5 }}{R_{\mathrm{u}, \text { Test }} / R_{\mathrm{u}, \text { Pre }}}$} & \multirow{2}{*}{$\begin{array}{l}\text { Jáger et al. } \\
R_{\mathrm{u}, \text { Test }} / R_{\mathrm{u}, \text { Pre }}\end{array}$} \\
\hline & $\begin{array}{c}V_{\mathrm{u}} \\
(\mathrm{kN})\end{array}$ & $\begin{array}{c}M_{\mathrm{u}} \\
(\mathrm{kN} \cdot \mathrm{m})\end{array}$ & $\begin{array}{c}V_{\mathrm{bW}} \\
(\mathrm{kN})\end{array}$ & $\begin{array}{c}V_{\mathrm{b}} \\
(\mathrm{kN})\end{array}$ & $\begin{array}{c}M_{\mathrm{f}} \\
(\mathrm{kN} \cdot \mathrm{m})\end{array}$ & $\begin{array}{c}M_{\text {eff }} \\
(\mathrm{kN} \cdot \mathrm{m})\end{array}$ & $\begin{array}{c}M_{\mathrm{pl}} \\
(\mathrm{kN} \cdot \mathrm{m})\end{array}$ & & \\
\hline VM-304-300ad1 & 199.7 & 89.8 & 187.8 & 218.7 & 89.8 & 106.3 & 115.2 & 1.05 & 1.05 \\
\hline VM-304-300ad1.5 & 147.3 & 110.3 & 163.4 & 184.2 & 93.0 & 109.0 & 117.5 & 1.05 & 1.06 \\
\hline VM-304-600ad1 & 249.7 & 224.6 & 238.6 & 265.5 & 247.6 & 277.0 & 346.3 & 1.02 & 1.02 \\
\hline Mean & - & - & - & - & - & - & - & 1.04 & 1.04 \\
\hline $\mathrm{COV}$ & - & - & - & - & - & - & - & 0.02 & 0.02 \\
\hline VM-2205-300ad1 & 336.6 & 151.2 & 291.4 & 348.8 & 170.5 & 193.1 & 217.1 & 1.08 & 1.08 \\
\hline VM-2205-300ad1.5 & 260.7 & 195.4 & 270.4 & 308.6 & 170.3 & 192.8 & 216.8 & 1.05 & 1.06 \\
\hline VM-2205-600ad1 & 420.3 & 377.7 & 381.7 & 430.8 & 419.8 & 433.2 & 608.4 & 1.06 & 1.06 \\
\hline Mean & - & - & - & - & - & - & - & 1.07 & 1.07 \\
\hline $\mathrm{COV}$ & - & - & - & - & - & - & - & 0.01 & 0.01 \\
\hline
\end{tabular}

\subsection{Design curve in GB 50017-2017}

The Chinese code for steel structures GB 50017-2017 [3] adopts the same expression but in a different form with that in EN 1993-1-5 for considering the bending and shear interaction effect. The expression is given by Eq. (4) and is shown in Fig. 22.

$$
\left(\frac{V}{0.5 V_{\mathrm{u}}}-1\right)^{2}+\frac{M-M_{\mathrm{f}}}{M_{\mathrm{eu}}-M_{\mathrm{f}}} \leq 1.0 \quad \text { for } M \geq M_{\mathrm{f}}
$$

where the bending capacity $M_{\mathrm{eu}}$ is obtained using a simplified procedure developed from the effective width method and the ultimate shear resistance $V_{\mathrm{u}}$ is calculated based on the simple post-critical method, taking into account the postbuckling capacity of the web panel. It is worth noting that the effective restraints from flanges are considered in the GB 50017-2017, by multiplying a constant factor of 1.23 in the calculation of shear buckling coefficient, which has also been described in Ref. [26]. Detailed comparisons for the tested specimens are shown in Fig. 21, while the cross-sectional capacities and comparison results are listed in Table 7. Though both the EN 1993-1-5 and GB 500172017 introduce the same interaction expression, separate design curves can be found in Fig. 21 as a result of the varied calculation formulae for the bending capacity and the shear resistance. By using the design formulae in GB 500172017 , it is revealed that satisfactory predictions are achieved for austenitic plate girders with a mean value of $R_{\mathrm{u}, \text { Test }} / R_{\mathrm{u}, \text { pre }}$ equals to 1.03 and a COV of 0.03 . While for the duplex plate girders, close agreement between the test and predicted results is also acquired, except for the slenderest specimen VM-2205-600ad1 (with highest value of slenderness $\lambda_{\mathrm{w}}$ ), which is mainly due to the underestimated shear buckling resistance for the slender duplex specimens.

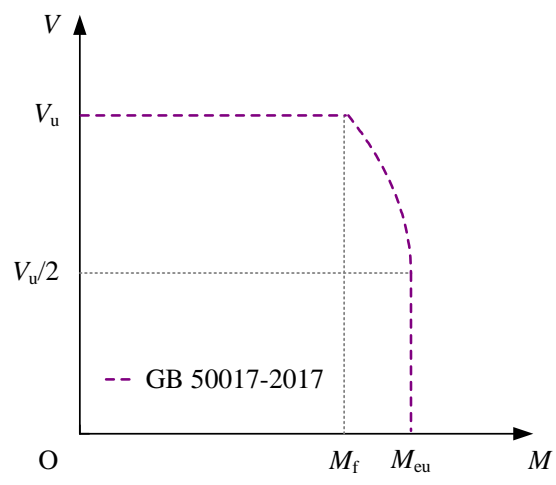

Fig. 22. M-V Interaction curve in GB 50017-2017 [3] 
Table 7

Comparison of test results with the M-V interaction curves in GB 50017-2017 [3], ANSI/AISC 360-16 [4] and SEI/ASCE 8-02 [20]

\begin{tabular}{|c|c|c|c|c|c|c|c|c|c|c|c|}
\hline \multirow[b]{2}{*}{ Specimens } & \multicolumn{2}{|c|}{ Test results } & \multicolumn{3}{|c|}{ GB 50017-2017 } & \multicolumn{3}{|c|}{ ANSI/AISC 360-16 } & \multicolumn{3}{|c|}{ SEI/ASCE 8-02 } \\
\hline & $\begin{array}{c}V_{\mathrm{u}} \\
(\mathrm{kN})\end{array}$ & $\begin{array}{c}M_{\mathrm{u}} \\
(\mathrm{kN} \cdot \mathrm{m})\end{array}$ & $\begin{array}{c}V_{\mathrm{u}} \\
(\mathrm{kN})\end{array}$ & $\begin{array}{c}M_{\mathrm{eu}} \\
(\mathrm{kN} \cdot \mathrm{m})\end{array}$ & $\begin{array}{c}R_{\mathrm{u}, \text { Test }} / \\
R_{\mathrm{u}, \mathrm{Pre}}\end{array}$ & $\begin{array}{c}V_{\mathrm{n}} \\
(\mathrm{kN})\end{array}$ & $\begin{array}{c}M_{\mathrm{n}} \\
(\mathrm{kN} \cdot \mathrm{m})\end{array}$ & $\begin{array}{c}R_{\mathrm{u}, \text { Test }} / \\
R_{\mathrm{u}, \mathrm{Pre}}\end{array}$ & $\begin{array}{c}V_{\mathrm{n}} \\
(\mathrm{kN})\end{array}$ & $\begin{array}{c}M_{\mathrm{n}} \\
(\mathrm{kN} \cdot \mathrm{m})\end{array}$ & $\begin{array}{c}R_{\mathrm{u}, \text { Test }} / \\
R_{\mathrm{u}, \text { Pre }}\end{array}$ \\
\hline VM-304-300ad1 & 199.7 & 89.8 & 197.4 & 103.7 & 1.01 & 205.1 & 115.2 & 0.93 & 205.1 & 103.7 & 1.15 \\
\hline VM-304-300ad1.5 & 147.3 & 110.3 & 188.5 & 106.2 & 1.07 & 195.3 & 117.5 & 0.81 & 177.2 & 106.2 & 1.12 \\
\hline VM-304-600ad1 & 249.7 & 224.6 & 248.5 & 291.8 & 1.00 & 306.4 & 286.0 & 0.80 & 242.7 & 280.9 & 1.16 \\
\hline Mean & - & - & - & - & 1.03 & - & - & 0.85 & - & - & 1.14 \\
\hline $\mathrm{COV}$ & - & - & - & - & 0.03 & - & - & 0.07 & - & - & 0.02 \\
\hline VM-2205-300ad1 & 336.6 & 151.2 & 338.9 & 195.9 & 0.99 & 359.3 & 202.2 & 0.89 & 310.4 & 189.9 & 1.20 \\
\hline VM-2205-300ad1.5 & 260.7 & 195.4 & 314.4 & 195.6 & 1.05 & 318.7 & 201.9 & 0.86 & 283.2 & 189.6 & 1.18 \\
\hline VM-2205-600ad1 & 420.3 & 377.7 & 345.6 & 527.0 & 1.22 & 534.9 & 424.2 & 0.83 & 382.8 & 432.9 & 1.25 \\
\hline Mean & - & - & - & - & 1.08 & - & - & 0.86 & - & - & 1.21 \\
\hline $\mathrm{COV}$ & - & - & - & - & 0.12 & - & - & 0.03 & - & - & 0.03 \\
\hline
\end{tabular}

\subsection{Design method in ANSI/AISC 360-16}

In the current American specification ANSI/AISC 360-16 for structural steel buildings, the interaction effect between bending moment and shear force is not explicitly addressed. The provisions for calculating the shear strengths of interior web panels with $a / h_{\mathrm{w}} \leq 3.0$ take into account the post-critical tension field action. Basler's analytical model (see Eq. (5)) is adopted for web panels in cross-sections satisfying $2 A_{\mathrm{w}} /\left(A_{\mathrm{ft}}+A_{\mathrm{fc}}\right) \leq 2.5$ and $h_{\mathrm{w}} / b_{\mathrm{ft}} \leq 6$ and $h_{\mathrm{w}} / b_{\mathrm{fc}} \leq 6$. Otherwise, a partial model of tension field action (given by Eq.(6)) is recommended without consideration for the bending and shear interaction.

$$
\begin{gathered}
V_{\mathrm{n}}=0.6 F_{\mathrm{y}} A_{\mathrm{w}}\left[C_{\mathrm{v} 2}+\frac{1-C_{\mathrm{v} 2}}{1.15 \sqrt{1+\left(a / h_{\mathrm{w}}\right)^{2}}}\right] \\
V_{\mathrm{n}}=0.6 F_{\mathrm{y}} A_{\mathrm{w}}\left[C_{\mathrm{v} 2}+\frac{1-C_{\mathrm{v} 2}}{1.15\left(a / h_{\mathrm{w}}+\sqrt{1+\left(a / h_{\mathrm{w}}\right)^{2}}\right)}\right]
\end{gathered}
$$

where $F_{\mathrm{y}}$ is the material yield strength of web panels; $A_{\mathrm{w}}$ is the area of web and $C_{\mathrm{v} 2}$ is the shear buckling coefficient given in Chapter G of ANSI/AISC 360-16. The tested plate girders satisfied the cross-sectional flange-to-web proportion limits of the Basler's analytical model, and hence Eq. (5) was used to calculate the shear strengths $V_{\mathrm{n}}$, as listed in Table 7, where the bending capacity $M_{\mathrm{n}}$ were determined based on the cross-section compactness, and were computed using the unified flexural resistance equations set out in Chapter F of ANSI/AISC 360-16. Separate comparisons for each tested specimen are shown in Fig. 21 and the normalised shear resistances $V_{\mathrm{u}} / V_{\mathrm{n}}$ versus bending capacity $M_{\mathrm{u}} / M_{\mathrm{n}}$ data points are depicted in Fig. 23. It can be seen that all test data points lie inside the design curves of ANSI/AISC 360-16, which indicates the apparently unsafe strength predictions obtained by the ANSI/AISC 360-16 provisions using the tension field method. The average test to predicted resistance ratios $R_{\mathrm{u}, \text { Test }} / R_{\mathrm{u}, \text { Pre }}$ are 0.85 and 0.86 for austenitic and duplex stainless steel plate girders, respectively, and the corresponding COVs are equal to 0.07 and 0.03. The unsafe predictions can be directly related to neglecting the bending and shear interaction effect. Meanwhile, the calculation formulae for the shear buckling coefficient $C_{\mathrm{v} 2}$ and the shear strength are proposed for carbon steels, without taking into account the material nonlinearity of stainless steels, which may also contribute to the overestimated predictions. 


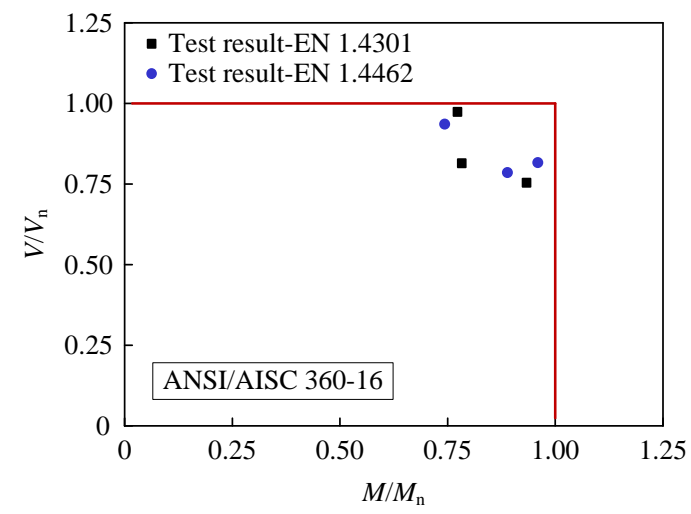

Fig. 23. Comparison of test results with design method in ANSI/AISC 360-16 [4]

\subsection{Design curve in SEI/ASCE 8-02}

The current American specifications SEI/ASCE 8-02 [20] for cold-formed stainless steel structures presents a linear $\mathrm{M}-\mathrm{V}$ interaction model for beams subjected to combined bending and shear, which is the same with that for coldformed carbon steel in AISI S100-16 [6]. Once the applied bending moment $M$ is higher than half of the available bending capacity $M_{\mathrm{n}}$ and the applied shear force $V$ exceeds $70 \%$ of the available shear strength $V_{\mathrm{n}}$, the following interaction expression should be satisfied:

$$
0.6 \frac{M}{M_{\mathrm{n}}}+\frac{V}{V_{\mathrm{n}}} \leq 1.3
$$

where the available bending capacity $M_{\mathrm{n}}$ is taken as the bending capacity for local buckling using the effective width method and the available shear strength $V_{\mathrm{n}}$ is obtained considering the postbuckling capacity. The cross-sectional properties determined by referring to the provisions in SEI/ASCE 8-02 are listed in Table 7 and separate comparisons for each tested plate girder are also presented in Fig. 21. The normalised shear plus bending test results, together with the SEI/ASCE 8-02 interaction curve, are depicted in Fig. 24 . The average test to predicted resistance ratios $R_{\mathrm{u}, \text { Test }} / R_{\mathrm{u}, \text { Pre }}$ are 1.14 and 1.21 for austenitic and duplex stainless steel plate girders, respectively, and the corresponding COVs are equal to 0.02 and 0.03. Compared to the assessed predictions from ANSI/AISC 360-16 in the above sub-section, the SEI/ASCE 8-02 specification leads to more conservative results, which can be attributed to the adoption of the linear M-V interaction expression, rather than the convex nonlinear interaction curves as used in EN 1993-1-5 and GB 500172017. However, despite the interaction buckling behaviour observed from the experiments in this study, the design specifications in SEI/ASCE 8-02 are capable of offering acceptable strength predictions for the tested stainless steel plate girders without considering the bending and shear interaction effect.

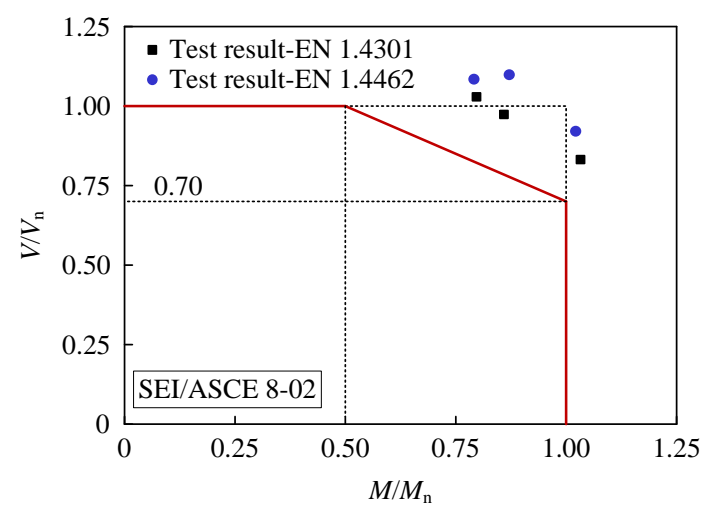

Fig. 24. Comparison of test results with M-V interaction curve in SEI/ASCE 8-02 [20] 


\section{Conclusions}

Comprehensive experimental tests performed to study the interaction behaviour of stainless steel plate girders under combined bending moment and shear force have been reported in this paper. A group of six plate girder specimens fabricated by austenitic and duplex stainless steel plates were tested. Prior to the tests, the initial geometric imperfections of each specimen were accurately measured by using a three-dimensional (3D) optical scanning system. A series of tensile and compressive coupon tests was carried out to determine the material properties of two adopted stainless steel grades, wherein the obtained strain hardening exponents were utilised to evaluate the existing calculation formulae. It has been demonstrated that closer predictions for the first strain hardening exponent $n$ can be achieved by using the $0.05 \%$ proof stress instead of the $0.01 \%$ proof stress.

All the six tested specimens failed by a combination of bending and shear buckling mode, and four of which had noticeable buckled shapes in the interior web panels, while the other two specimens exhibited local flange buckling combined with web buckling. By analysing the obtained surface strains of web panels, it was revealed that apparent interaction effect of combined bending moment and shear force within the interior web panels was obtained, and the neutral axis of web panel was in a state of pure shear prior to the onset of local buckling. It was also indicated that the shear stresses plus the compressive stresses generated by the bending moment can lead to premature local buckling in the web panel. The critical local web buckling occurred before reaching the material yield strain, yet all tested specimens exhibited significant postbuckling capacities. The existing M-V interaction methods in EN 1993-1-5, GB 50017-2017, ANSI/AISC 360-16, SEI/ASCE 8-02, and the proposal of Jáger et al were all assessed by the obtained ultimate resistances. It can be concluded that acceptable yet slightly conservative strength predictions were achieved for the tested stainless steel plate girders by the design methods in EN 1993-1-4+A1 for stainless steel structures plus using the M-V interaction curves in EN 1993-1-5 for carbon steel plate girders and the proposal of Jáger et al. The Chinese code GB 50017-2017 for carbon steel structures provided safe predictions for the tested stainless steel plate girders. The current ANSI/AISC 360-16 specification for carbon steel structures without considering the M-V interaction effect resulted in unsafe estimations for the tested stainless steel plate girders, which highlights the need for developing more accurate and suitable design guidance for stainless steel plate girders. Moreover, the SEI/ASCE 8-02 for stainless steel cold-formed sections taking into account the $\mathrm{M}-\mathrm{V}$ interaction effect yielded rather conservative results for the tested stainless steel plate girders.

Further comprehensive numerical analysis is currently underway based upon the obtained experimental results, to explore the critical buckling behaviour and the ultimate capacity, and to develop more suitable design rules for stainless steel plate girders with combined bending and shear interaction.

\section{Acknowledgements}

The financial supports from the Natural Science Foundation of Hubei Province (Grant no. 2018CFB441), National Natural Science Foundation of China (Grant no. 51508424), the Fundamental Research Funds for the Central Universities (Grant no. 2042017gf0047) are greatly acknowledged by the authors. The first author appreciates the financial support from the China Scholarship Council for sponsoring studying at UPC, and the corresponding author gives thanks to the support from the Youth Talent Training Programme by Wuhan University in the year of 2018.

\section{References}

[1] K. Basler, Strength of plate girders under combined bending and shear, J. Struct. Div. ASCE 87 (7) (1961) 181-197.

[2] EN 1993-1-5, Eurocode 3: Design of steel structures-Part 1.5: Plated structural elements, CEN, 2006.

[3] GB 50017-2017, Standard for design of steel structures, China Architecture \& Building Press, Beijing, 2018 (in Chinese).

[4] ANSI/AISC 360-16, Specification for structural steel buildings, AISC, 2016.

[5] AASHTO, LRFD Bridge design specifications, $8^{\text {th }}$ ed., AASHTO, 2017. 
[6] AISI S100-16, North American specification for the design of cold-formed steel structural members, AISI, 2016.

[7] C.R. Hendy, F. Presta, Transverse web stiffeners and shear moment interaction for steel plate girder bridges, Atkins Technical J. 2008, $13-26$.

[8] F. Sinur, D. Beg, Moment-shear interaction of stiffened plate girders - Tests and numerical model verification, J. Constr. Steel Res. 85 (2013) 116-129.

[9] F. Sinur, D. Beg, Moment-shear interaction of stiffened plate girders - Numerical study and reliability analysis, J. Constr. Steel Res. 88 (2013) 231-243.

[10] B. Jáger, B. Kövesdi, L. Dunai, I-girders with unstiffened slender webs subjected by bending and shear interaction, J. Constr. Steel Res. 131 (2017) 176-188.

[11] B. Jáger, B. Kövesdi, L. Dunai, Bending and shear buckling interaction behaviour of I-girders with longitudinally stiffened webs, J. Constr. Steel Res. 145 (2018) 504-517.

[12] F. Shahabian, T.M. Roberts, Behaviour of plate girders subjected to combined bending and shear loading, Scientia Iranica 15 (1) (2008) 16-20.

[13] S. Lee, D. Lee, C. Yoo, Flexure and shear interaction in steel I-girders, J. Struct. Eng. ASCE 139 (11) (2013) $1882-1894$.

[14] N.R. Baddoo, Stainless steel in construction: a review of research, applications, challenges and opportunities, J. Constr. Steel Res. 64 (2008) 1199-1206.

[15] B. Young, W.M. Lui, Tests of cold-formed high-strength stainless steel compression members, Thin-Walled Struct. 44 (2) (2006) 224-234.

[16] J. Becque, M. Lecce, K.J.R. Rasmussen, The direct strength method for stainless steel compression members, J. Constr. Steel Res. 64 (11) (2008) 1231-1238.

[17] B.F. Zheng, X. Hua, G.P. Shu, Tests of cold-formed and welded stainless steel beam-columns, J. Constr. Steel Res. 111 (2015) 1-10.

[18] L. Yang, M. Zhao, T.M. Chan, F. Shang, D. Xu, Flexural buckling of welded austenitic and duplex stainless steel I-section columns, J. Constr. Steel Res. 122 (2016) 339-353.

[19] EN 1993-1-4+A1, Eurocode 3: Design of steel structures-Part 1.4: General rules-supplementary rules for stainless steel, CEN, 2015.

[20] SEI/ASCE 8-02, Specification for the design of cold-formed stainless steel structural members, ASCE, 2002.

[21] CECS 410:2015, Technical specification for stainless steel structures, China Planning Press, Beijing, 2015 (in Chinese).

[22] A. Olsson, Stainless steel plasticity-material modeling and structural application [PhD dissertation], Lulea University of Technology, Sweden, 2001.

[23] E. Real, E. Mirambell, I. Estrada, Shear response of stainless steel plate girders, Eng. Struct. 29 (7) (2007) 1626-1640.

[24] I. Estrada, E. Real, E. Mirambell, General behaviour and effect of rigid and non-rigid end post in stainless steel plate girders loaded in shear. Part I: Experimental study, J. Constr. Steel Res. 63 (7) (2007) 970-984.

[25] N. Saliba, L. Gardner, Experimental study of shear response of lean duplex stainless steel plate girders, Eng. Struct. 46 (2013) $375-$ 391.

[26] X.W. Chen, H.X. Yuan, X.X. Du, Y. Zhao, J. Ye, L. Yang, Shear buckling behaviour of welded stainless steel plate girders with transverse stiffeners, Thin-Walled Struct. 122 (2018) 529-544.

[27] H.X. Yuan, X.W. Chen, M. Theofanous, Y.W. Wu, T.Y. Cao, X.X. Du, Shear behaviour and design of diagonally stiffened stainless steel plate girders, J. Constr. Steel Res. 153 (2019) 588-602.

[28] H.X. Yuan, Y.Q. Wang, Y.J. Shi, L. Gardner, Residual stress distributions in welded stainless steel sections, Thin-Walled Struct. 79 (2014) 38-51.

[29] M.A.B. Ebrahim, 3D laser scanners' techniques overview, Int. J. Sci. Res. 4 (10) (2015) 323-331.

[30] H.X. Yuan, Y.Q. Wang, Y.J. Shi, L. Gardner, Stub column tests on stainless steel built-up sections, Thin-Walled Struct. 83 (2014) $103-114$.

[31] I. Arrayago, E. Real, L. Gardner, Description of stress-strain curves for stainless steel alloys, Mater. Des. 87 (2015) $540-552$.

[32] W.P. Vann, J. Sehested, Experimental techniques for plate buckling, in: Proceedings of the 2nd specialty conference on cold-formed steel structures, University of Missouri-Rolla, USA, October, 1973.

[33] K.R. Venkataramaiah, J. Roorda, Analysis of local plate buckling experimental data, in: Proceedings of the 6th international specialty conference on cold-formed steel structures, University of Missouri-Rolla, USA, November, 1982. 